\title{
2. Epidemiology of infectious complications in cancer patients
}

Teresa Zembower

\section{Introduction}

Infectious complications are a serious cause of morbidity and mortality in cancer patients, especially those with underlying hematologic malignancies. Several large studies have estimated that $70-75 \%$ of deaths in patients with acute leukemia are caused by infection, with or without hemorrhage [1-3]. Fewer data exist on infectious mortality in patients with solid organ tumors; however, approximately $50 \%$ of these patients are estimated to have an infection as either the primary or an associated cause of death $[4,5]$. Because patients with underlying malignancies are a heterogeneous group, an epidemiologic review of infections in these patients must take into account the diversity of the patient population. The nature of the underlying malignancy, the immunodeficiencies associated with it, and the treatments directed against it are all important determinants of infection.

For ease of understanding, the factors that predispose to infection are divided into those that are host associated and those that are treatment associated. Host-associated factors include deficiencies of cellular and humoral immunity, disrupted anatomic barriers, central nervous system dysfunction, prior splenectomy, and alterations in the microbial flora. Treatmentassociated factors include surgery, radiation, and chemotherapy, antibiotic use, and diagnostic or invasive procedures, including blood transfusions and bone marrow infusions (Table 1). Clearly, more than one predisposing factor may exist simultaneously in a given patient. To a large extent, however, these risk factors are associated with specific infectious pathogens, and an understanding of each individual risk factor can help direct diagnosis and empiric therapy (Table 2).

\section{Host-associated factors}

\subsection{Granulocytopenia}

Granulocytopenia (neutropenia) is defined as an absolute neutrophil count (ANC) lower than 1000 or $500 \mathrm{cells} / \mathrm{mm}^{3}$ and is the single most important risk 
Table 1. Factors predisposing to infection in cancer patients

\begin{tabular}{|c|c|}
\hline Factor & Comments \\
\hline \multicolumn{2}{|l|}{ Host associated } \\
\hline Granulocytopenia & $\begin{array}{l}\text { Absolute neutrophil count less than } 1000 \text { or } \\
500 \text { cells } / \mathrm{mm}^{3} ; \text { most important risk factor for } \\
\text { infection in cancer patients }\end{array}$ \\
\hline Cell-mediated immunodeficiency & Defective monocyte/macrophage or T-cell function \\
\hline Humoral immunodeficiency & $\begin{array}{l}\text { Defective B-cell function, leading to loss of opsonizing } \\
\text { antibodies }\end{array}$ \\
\hline Disrupted anatomic barriers & $\begin{array}{l}\text { Caused by the invading malignancy or the treatments } \\
\text { directed against it }\end{array}$ \\
\hline Splenectomy & $\begin{array}{l}\text { Loss of monocytes, macrophages, B lymphocytes, and } \\
\text { properidin (a component of the alternate } \\
\text { complement pathway) }\end{array}$ \\
\hline Central nervous system dysfunction & $\begin{array}{l}\text { Loss of gag reflex, impaired micturition, and loss of } \\
\text { mobility }\end{array}$ \\
\hline Changes in microbial flora & $\begin{array}{l}\text { Occur secondary to the severity of the underlying } \\
\text { illness, invasive procedures, and antimicrobial usage }\end{array}$ \\
\hline \multicolumn{2}{|l|}{ Treatment associated } \\
\hline Surgery & $\begin{array}{l}\text { Especially pelvic, gastrointestinal, and maxillofacial; } \\
\text { largest interventions carry greatest infectious risk }\end{array}$ \\
\hline Radiation & $\begin{array}{l}\text { Preoperative irradiation leads to fistula formation and } \\
\text { impaired wound healing }\end{array}$ \\
\hline Chemotherapy & $\begin{array}{l}\text { Damages anatomic barriers and leads to cytopenias in } \\
\text { a dose-related fashion }\end{array}$ \\
\hline Antibiotics & Rapidly and radically alter microbial flora \\
\hline \multicolumn{2}{|l|}{ Diagnostic and invasive procedures } \\
\hline Central venous catheters & $\begin{array}{l}\text { Bacterial colonization occurs within days of insertion; } \\
15-20 \% \text { develop overt infection }\end{array}$ \\
\hline $\begin{array}{l}\text { Blood transfusions and bone } \\
\text { marrow infusions }\end{array}$ & $\begin{array}{l}\text { Infection occurs most commonly through collection of } \\
\text { specimens from infected donors }\end{array}$ \\
\hline
\end{tabular}

factor for the development of bacterial infection in cancer patients. Patients with acute leukemia, those who have received intensive myelosuppressive therapies for their underlying malignancies or as part of their bone marrow transplantation, or those with aplastic anemia are most likely to develop or present with granulocytopenia [6]. Patients with lymphoma may also have marrow involvement severe enough to result in neutropenia [7]. Although less common, solid organ tumors, such as metastatic carcinoma of the breast, prostate, lung, adrenal, thyroid, and kidney, can all infiltrate the bone marrow and result in granulocytopenia [8].

The incidence of infection increases when the neutrophil count falls below 500 cells $/ \mathrm{mm}^{3}$. Patients with severe neutropenia, having an ANC below 100 cells $/ \mathrm{mm}^{3}$, represent a unique subset of patients who are at highest risk of infection [9]. This level of severe neutropenia decreases the mobilization of white blood cells to the site of inflammation. Therefore, when bacterial pathogens are encountered, the usual acute pyogenic response is muted or absent, making it difficult for these patients to control the spread of an infection [10]. 
Table 2. Predisposing factors and their associated infections

Factor

Neutropenia

Cell-mediated immunodeficiency

Humoral immunodeficiency

Disruption of anatomic barriers

Splenectomy
Infectious pathogen

Bacteria

Staphylococcus aureus

Staphylococcus epidermidis

Alpha-hemolytic streptococci

Escherichia coli

Klebsiella spp.

Pseudomonas aeruginosa

Viruses

Herpes simplex

Varicella-zoster

Cytomegalovirus

Yeast/fungi

Candida spp.

Aspergillus spp.

Bacteria

Listeria monocytogenes

Salmonella spp.

Nocardia asteroides

Mycobacteria

Legionella pneumophila

Viruses

Herpes simplex

Varicella-zoster

Cytomegalovirus

Epstein-Barr

Yeast

Cryptococcus neoformans

Histoplasma capsulatum

Coccidioides immitis

Protozoa

Pneumocystis carinii

Toxoplasma gondii

Cryptosporidium

Helminth

Strongyloides stercoralis

Streptococcus pneumoniae

Haemophilus influenzae

Skin

Staphylococcus aureus Staphylococcus epidermidis Streptococcus pyogenes

Oral cavity/nasopharynx

Anaerobes

Streptococci

Haemophilus influenzae

Gastrointestinal tract

Enterobacterianceae

Fungi

Female genital tract

Enterobacteriaceae

Anaerobic GNB

Enterococci

Clostridia spp.

Streptococcus pneumoniae

Haemophilus influenzae

Neisseria meningitidis 
Table 2. (continued)

\begin{tabular}{ll}
\hline Factor & Infectious pathogen \\
\hline Central venous catheters & Staphylococci \\
Streptococci \\
Bacillus spp. \\
Corynebacterium spp. \\
Blood transfusions & Candida albicans \\
& Mycobacterium chelonei \\
& Mycobacterium fortuitum \\
Bacteria & P. fluorescens/putida \\
Yersinia enterocolitica \\
Viruses \\
Hepatitis viruses \\
HIV \\
Epstein-Barr \\
Cytomegalovirus \\
Protozoa \\
Leishmaniasis \\
Trypanosomiasis \\
Chagas' disease \\
Microfilarial diseases \\
Malaria \\
Babesia microti
\end{tabular}

The rapidity in the decline of the neutrophil count is also important in determining the risk of infection. For example, a rapidly falling count is much more likely to be associated with infection than is either a slowly declining count, as observed with syndromes such as cyclic neutropenia, or a stable neutropenia, as is often seen in patients with stable aplastic anemia or benign idiopathic neutropenia [11].

The duration of neutropenia also correlates with the risk of infection. In fact, once a patient is febrile and neutropenic, the duration of the neutropenia is a stronger predictor of infection than is the absolute neutrophil count [12]. Virtually all patients who remain severely neutropenic (ANC less than 100 cells $/ \mathrm{mm}^{3}$ ) will develop an infection within 3 weeks $[3,8]$.

Patients whose neutrophil counts are falling are also at greater risk than those patients whose counts are recovering. For example, the patient with an ANC of 500 cells $/ \mathrm{mm}^{3}$ who has just received cytotoxic chemotherapy and is expected to be severely neutropenic within a few days is at greater risk than is the patient whose neutrophil count is $200 \mathrm{cells} / \mathrm{mm}^{3}$ and rising. A large multicenter study by the European Organization for Research on Treatment of Cancer (EORTC) demonstrated that the change in granulocyte count was the most important factor in determining success or failure of antibiotic therapy for gram-negative bacteremia. Only $22 \%$ of patients whose granulocyte count did not rise by at least 100 cells $/ \mathrm{mm}^{3}$ during therapy were successfully treated, whereas $88 \%$ of those whose count rose by at least 100 cells $/ \mathrm{mm}^{3}$ completely improved [13]. 
Several studies have examined the sites and types of infection that occur in the neutropenic host. The neutropenic cancer patient usually has a variety of other predisposing factors that act together to increase the risk of infection. Cytotoxic chemotherapy damages the mucosal membranes of the alimentary and respiratory tracts, drug-induced vomiting with stomach acid reflux predispose to infection in the distal esophagus, underlying periodontal disease or reactivation of herpes virus can serve as a cofactor for the development of oral infection, frequent bowel movements and the associated high pressure damage the anal mucosa, and vascular catheters and other invasive procedures damage the integument [14].

The infecting organisms in neutropenic patients are usually the organisms that colonize these particular sites (Figure 1). Organisms that colonize the lower gastrointestinal tract, such as Escherichia coli, Klebsiella pneumioniae, and Pseudomonas aeruginosa, are the most commonly encountered gramnegative pathogens causing infections in these patients. Staphylococcus epidermidis, Staphylococcus aureus, and $\alpha$-hemolytic streptococci colonize the skin and upper respiratory tract and cause the majority of gram-positive bacterial infections [15]. However, the microbial flora changes with prolonged hospitalization, largely as a result of antibiotic selective pressure. Gramnegative bacilli begin to colonize the upper respiratory tract, resulting in gram-negative bacterial infections of the pharynx, lung, and esophagus [16].

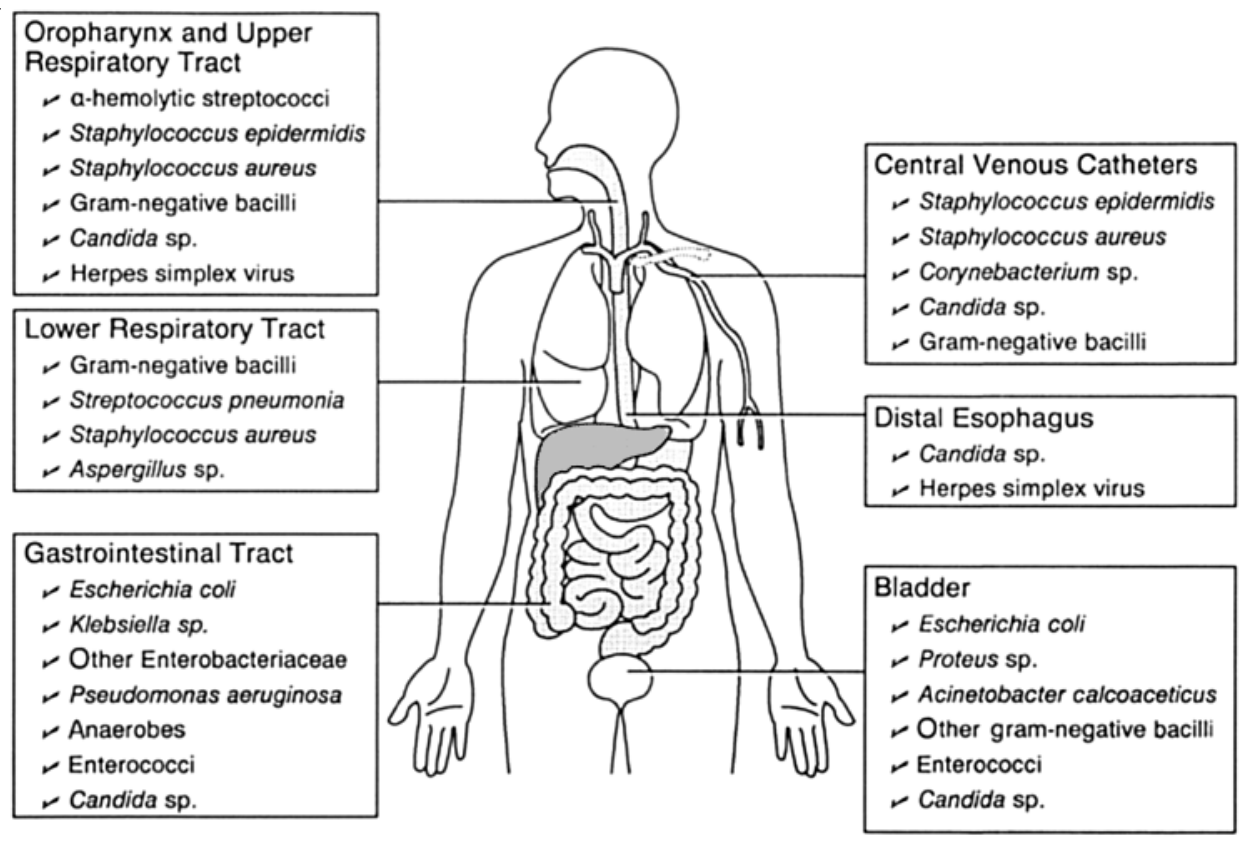

Figure 1. Sites and types of infections in the neutropenic host. 
Specific antibiotics, such as the fluoroquinolones, predispose to colonization with streptococci and quinolone-resistant gram-negative bacteria [17]. Other bacteria, such as Serratia marcescens, Proteus spp., Enterobacter spp., Aeromonas spp., and Acinetobacter calcoaceticus, and fungi such as Candida spp. and Aspergillus spp., less frequently colonize these patients and can cause infections in the neutropenic host $[8,18-21]$.

\subsection{Cell-mediated immunity}

Cell-mediated immunity depends upon the interaction of $\mathrm{T}$ lymphocytes with the monocyte/macrophage system. Working together, these cells enhance the phagocytosis and killing of intracellular pathogens. T-lymphocyte precursors are released from the bone marrow and migrate to the thymus gland, where maturation into $\mathrm{T}$ lymphocytes occurs. The mature $\mathrm{T}$ lymphocytes then exit the thymus and are present in the circulation, the lymph nodes, and the spleen. Upon antigenic stimulation, T lymphocytes secrete lymphokines, which act in two important ways. One group, the immunoregulatory lymphokines, modulates the function of both $\mathrm{T}$ and $\mathrm{B}$ cells. The second group, the inflammatory lymphokines, regulates the function of macrophages. The two most important lymphokines are migration inhibitory factor (MIF) and macrophage activating factor (MAF). MIF slows the rate of migration of macrophages, keeping them at the site of inflammation. MAF greatly enhances the killing capacity of macrophages for intracellular organisms.

Mononuclear phagocytes arise in the bone marrow from immature precursors, undergo differentiation in the marrow as promonocytes, and are then released into the circulation as monocytes. Monocytes remain in the circulation for only a brief time (half-life of 22-24 hours), after which they leave the blood to become tissue macrophages. These macrophages exist throughout the body in the brain, lung, bone, liver, kidney, spleen, and skin. Under the direction of lymphokines, macrophages become activated. In this form, the macrophages demonstrate increased phagocytosis and microbial killing. In fact, the activated macrophages are responsible for the killing of many intracellular pathogens that are resistant to killing by monocytes, quiescent macrophages, and neutrophils [22,23].

Hodgkin's disease and HIV infection are the prototypical illnesses associated with cellular immune dysfunction [24,25]. However, impairment of cellmediated immunity can occur with most cancers, including acute and chronic leukemia; solid organ tumors; such as breast, lung, brain, gastrointestinal tract, and urogenital tumors and following bone marrow transplantation [26-33]. Alternatively, irradiation and certain medications, such as azathioprine, cyclosporine, and corticosteroids, can result in cellular immunodeficiency [34-36].

Several predominantly intracellular pathogens are associated with deficiencies of cell-mediated immunity. These include the bacteria Listeria monocytogenes, Salmonella spp., Nocardia asteroides, mycobacteria (both 
M. tuberculosis and the nontuberculous mycobacteria), and Legionella; the yeast Cryptococcus neoformans, Histoplasma capsulatum, Coccidioides immitis, and Pneumocystis carinii; the viruses varicella-zoster virus (VZV), cytomegalovirus (CMV), Ebstein-Barr virus (EBV), herpes simplex virus (HSV), and adenovirus; the protozoa Toxoplasma gondii and Cryptosporidium; and one helminth, Strongyloides stercoralis [10,37-47].

\subsection{Humoral immunity}

B lymphocytes are the cells primarily involved in humoral immunity. Like $T$ lymphocytes, they arise from precursor stem cells in the bone marrow. In humans, B lymphocytes mature in gut-associated lymphoid tissue of Peyer's patches in the ileum, in the submucosal lymphoid follicles of the appendix, and in the bone marrow. Following maturation, they are distributed to the spleen and lymph nodes. Under proper antigenic stimulation, they differentiate into immunoglobulin (antibody)-producing plasma cells. These plasma cells produce opsonizing antibodies. Coating or opsonizing certain bacteria, particularly encapsulated bacteria, greatly enhances their phagocytosis. Patients with defects in humoral immunity lack opsonizing antibodies to the common encapsulated pyogenic bacteria and thus are susceptible to infections with organisms such as Streptococcus pneumoniae and Haemophilus influenzae [22].

Multiple myeloma is the neoplasm classically associated with altered humoral immunity. Multiple myeloma patients are hypogammaglobulinemic, producing normal immunoglobulins at only $10 \%$ of the normal rate. Interestingly, some myeloma patients have no infections with $S$. pneumoniae. These patients produce the specific opsonizing antibodies needed to defend them, whereas other myeloma patients who do not produce the necessary opsonizing antibodies have recurrent pneumococcal infections with the same or different strains [48-50].

Waldenström's macroglobulinemia and chronic lymphocytic leukemia are also neoplasms affecting B lymphocytes. They too are characterized by defective humoral immunity [51,52]. Likewise, patients who undergo prolonged immunosuppresive therapies, such as those used to prevent graft-versus-host disease (GVHD) following allogeneic bone marrow transplantation, may not regain their ability to synthesize $\operatorname{IgG}$ and $\operatorname{IgM}$ for up to 1 year, and the synthesis of IgA may remain depressed for years [53,54].

\subsection{Anatomic barriers}

The anatomic barriers of the skin and soft tissues are essential for protection of the immunocompromised host. These barriers can be damaged by invasion from the malignancy itself or by treatments directed at the malignancy, such as radiation and cytotoxic chemotherapy. Primary or metastatic tumors of the skin can disrupt this important anatomic barrier. These tumors increase the 
risk of bacteremia with organisms such as Staphylococcus aureus, Staphylococcus epidermidis, and Streptococcus pyogenes, which colonize the skin [55]. Mucous membranes of the oral cavity and nasopharynx may be affected by invasive carcinomas, resulting in local infection in the mouth, nose, throat, or sinuses. This predisposes to anaerobic necrotizing infections, streptococcal infections, and infections due to $H$. influenzae. These infections can spread to the meninges, causing meningitis, or can locally invade the sinuses, causing osteomyelitis with or without subsequent cerebral abscess. The mucous membranes of the gastrointestinal tract can be disrupted by invasive carcinomas, causing local abscess formation, bacteremia with gram-negative bacilli, or perforation with resulting peritonitis. The possibility of fungal infection increases if these patients have received broad-spectrum antibiotics. Disruption of barriers in the female genital tract can occur with gynecological malignancies. Pathogens such as anaerobic gram-negative bacilli, enteric gram-negative bacilli, Clostridia spp., and enterococci will occasionally invade the bloodstream, causing systemic infection $[8,56]$. Mucous membranes can also be damaged by radiation or chemotherapy. Regimens that include cytosine arabinoside, anthracyclines, methotrexate, 6-mercaptopurine, and 5 -fluorouracil are most likely to cause gastrointestinal mucositis and stomatitis [5].

In addition to damaging mucous membranes, malignancies can cause obstruction of various orifices or passages, leading to stasis of body fluids and subsequent infection. Carcinoma of the prostate, ovary, cervix, and rectum commonly obstruct the urinary tract, whereas central nervous system tumors can impair micturition, all leading to urinary retention and recurrent urinary tract infection. Primary or metastatic lung tumors can obstruct the bronchi, causing postobstructive pneumonia and abscess formation. Obstruction of the biliary tract by lymphoma or pancreatic cancer predisposes to ascending cholangitis. Tumors that obstruct the blood vessels can cause septic thrombophlebitis or ischemia, which predispose to infection $[5,8]$.

\subsection{Splenectomy}

The spleen contains large numbers of monocytes, macrophages, and B lymphocytes, enabling it to perform many important immune functions. First, the spleen filters particles from the bloodstream using strategically positioned tissue macrophages. These macrophages can engulf circulating, opsonized organisms, helping to rid the body of many encapsulated bacteria [57]. These macrophages can also remove non-opsonized bacteria, making the spleen critically important to the individual who encounters infection with a new serotype of pneumococci to which he or she is not immune. The spleen is also important in humoral immunity; it is here that the immunoglobulin response primarily takes place. In addition, splenectomized patients have reduced levels of properidin, an important component of the alternate complement pathway. 
Patients who have undergone splenectomy are at increased risk for infections with encapsulated bacteria such as Streptococcus pneumoniae, $H$. influenzae, and Neisseria meningitidis. In fact, patients who undergo splenectomy for staging or treatment of a hematologic malignancy have approximately a $5 \%$ risk of developing overwhelming sepsis at some time during their lifetime [58]. A syndrome of overwhelming pneumococcal sepsis has been described in splenectomized children, and much less commonly in splenectomized adults [59]. For this reason, patients who undergo splenectomy should receive the polyvalent pneumococcal vaccine, preferably prior to splenectomy in order to obtain the best immune response [60].

Another group of patients who are at increased risk of invasive pneumococcal infections are those who have undergone allogeneic bone marrow transplantation. The reasons are twofold: (1) these patients demonstrate a decreased ability to synthesize $\operatorname{IgG}$ and $\operatorname{IgM}$, and (2) they fail to switch from IgM to IgG production if chronic GVHD develops, producing a state of functional asplenia $[53,61]$.

\subsection{Central nervous system dysfunction}

Primary or metastatic tumors of the central nervous system (CNS) can predispose to a variety of infections. Patients who have either a partial or complete loss of their gag reflex are at greater risk for aspiration pneumonia. Impaired micturition is a common finding in these patients and can lead to urinary retention and recurrent urinary tract infections. Likewise, patients with impaired mobility are predisposed to skin breakdown, which can result in decubitus ulcers and osteomyelitis. Interestingly, meningitis, encephalitis, and brain abscesses are uncommon in patients with CNS tumors unless related to problems of surgery $[58,62]$.

\subsection{Changes in microbial flora}

Dramatic changes in microbial flora can occur in debilitated patients. The severity of the underlying illness, invasive procedures, and antibiotic usage are all associated with alterations in the normal flora. A study by Johanson and colleagues demonstrated that severity of illness and antimicrobial usage can both change the normal flora. Throat cultures were obtained from normal volunteers and from patients hospitalized on a psychiatric ward, an orthopedic ward, and two medical wards. The patients on both medical wards had severe underlying medical illnesses; on one ward they were receiving antibiotics and on the other they were not. Throat cultures from the normal volunteers and the psychiatric patients revealed normal flora. However, the throat cultures from $16 \%$ of the orthopedic patients, $57 \%$ of the medical patients without antibiotics, and $80 \%$ of the medical patients with antibiotics revealed gramnegative bacilli [16]. This suggests that severity of illness and antibiotics, not hospitalization per se, are associated with changes in endogenous flora. 
Invasive procedures, such as placement of urinary or intravascular catheters or tracheostomies, can also alter normal flora. Urinary and intravascular catheters can become colonized with organisms that track along the catheter and colonize these normally sterile body sites. Patients with tracheostomies generally become colonized with gram-negative bacteria within a few days following placement. If pneumonia develops, it is usually due to these same bacterial pathogens with which the patient is colonized. Indeed, the majority of patients are infected with the organisms with which they are colonized; however, $50 \%$ of these organisms are acquired after hospitalization [14]. Studies have demonstrated that serial axillary surveillance cultures grow primarily Staphylococcus epidermidis and Corynebacterium spp. on admission. As the illness and the hospitalization progress, the resident flora shifts toward gram-negative bacteria and yeast such as Candida albicans $[10,63]$.

Of all the predisposing conditions, antibiotic use is the single most important factor leading to changes in host flora. Although necessary for both prophylaxis and treatment of infections, antimicrobial agents can cause rapid and radical alterations in endogenous flora. One of the most common examples is Clostridium difficile colonization and infection induced by antibiotic therapy $[64,65]$. However, broad-spectrum antibiotics are more apt to suppress normal, noninvasive flora, particularly anaerobes, and to cause a shift toward gram-negative bacteria and yeast. In one study, surveillance cultures were monitored in 10 patients receiving ampicillin for 3 weeks. Nine of these patients became rapidly colonized with ampicillin-resistant gram-negative rods, and several isolates were multiply drug resistant. Only one patient in the control group acquired a multidrug-resistant organism [10]. Likewise, the incidence of fungal infections is related to prophylaxis and treatment with broad-spectrum antibiotics. For example, fluconazole prophylaxis has resulted in the development of resistant strains of $C$. albicans and Torulopsis glabrata [66-69] and to outbreaks of inherently fluconazole-resistant Candida krusei $[70,71]$.

To understand the changing microbial flora, it is important to understand a concept known as colonization resistance. Individuals are colonized with noninvasive flora that, in a sense, can be considered "protective." This normal flora prevents colonization and subsequent infection with more invasive, pathogenic bacteria. Patients who have lost their normal flora, such as those receiving broad-spectrum antibiotics, are at greater risk of colonization and infection with these more invasive organisms. In an animal model of infection, van der Waaij elegantly depicts this phenomenon. In this study, three groups of mice were used: one group was rendered completely germ-free, a second group retained their anaerobic flora but were rendered free of aerobes, and the third group of normal mice served as the control. The mice were given different oral doses of streptomycin-resistant $E$. coli for ease of detection, and persistent colonization was determined by evaluation of fecal flora. The control group required $10^{7} \mathrm{E}$. coli to become persistently colonized, the mice with only anaerobic flora required approximately $10^{5} \mathrm{E}$. coli, and the germ-free 
mice, who had no colonization resistance, required only $10^{1}$ to $10^{2}$ E. coli, confirming the importance of colonization resistance [72].

\section{Treatment-associated factors}

Although essential to patient care, no procedure or treatment is without risk. The following treatment-associated factors have all been shown to predispose patients with underlying malignancies to an increased risk of infection.

\subsection{Surgery}

Extensive surgery, especially in the pelvic, gastrointestinal, or maxillofacial regions, increases the risk of infection in cancer patients [8]. Although the procedures are often necessary, especially for advanced invasive tumors, they remove large areas of otherwise protective tissue and disrupt anatomic barriers that predispose to leakage of material already containing bacterial flora. The infectious complications following surgery vary depending on the site and extent of the operation, and the type of procedure performed; even so, postoperative infections have been shown in one series to be twice as common in cancer versus noncancer patients [73].

The site and specific type of surgery is an important determinant of infection. For example, intraabdominal procedures such as Hartman's operation, which involves sigmoid resection with a diverting colostomy [74], are frequently complicated by infection in patients with underlying malignancies [75]. Likewise, craniotomy in cancer patients who have previously had an arteriovenous shunt placed predisposes to an increased risk of meningitis and/or sepsis [76]. Extensive surgery of the paranasal sinuses has also been shown to predispose to Pseudomonas meningitis in these patients [77]. The extent of the operation plays a major role in determining infection. As expected, the largest interventions are associated with the maximum risk. Other factors such as obesity can also increase the infectious risk in these patients [78].

The surgical management of the patient with neutropenic enterocolitis (typhlitis) is a frequently encountered, although controversial, issue. A review of 438 leukemic patients demonstrated a $13 \%$ incidence of major gastrointestinal complications, and neutropenic enterocolitis was one of the most ominous [79]. Along with the increased risk of infection, these neutropenic and usually thrombocytopenic patients have a high risk of operative mortality from the surgery itself. Consequently, the care of these patients should be individualized. Non-operative management with bowel rest, decompression, nutritional support, and broad-spectrum antibiotics is usually recommended initially. Operative intervention is often reserved for patients with bowel perforation or for those whose condition clinically deteriorates despite conservative management [80]. 
Splenectomy, as previously outlined, increases the risk of infection by depressing cell-mediated and humoral immunity. In fact, except in young children, the splenectomy itself does not pose an increased risk of infection. In splenectomized patients, the specific type and severity of the underlying malignancy is the major determinant of infection $[26,81]$.

\subsection{Radiation}

In addition to surgery, preoperative irradiation increases the risk of infection. In one series, preoperative irradiation given to patients undergoing surgery for breast cancer was associated with a twofold increase in infectious complications. However, postoperative irradiation was not associated with an increased risk [82]. Infection is also the most common complication in patients who receive preoperative irradiation prior to oncologic surgery of the upper respiratory or gastrointestinal tract. This is predominantly due to fistula formation or impaired wound healing [83]. In addition to causing local tissue damage, radiation can also result in stenosing lesions, leading to obstruction [8].

Radiation of the spleen or lymph nodes can depress cell-mediated immunity and antibody production. Total body irradiation predictably results in substantial depression of cellular immune function for months to years. Finally, radiation can also result in marrow depression and neutropenia [62].

\subsection{Chemotherapy}

Chemotherapeutic agents predispose to infection in a variety of ways (Table 3). Many of these agents damage the body's anatomic barriers. Most notably, they can cause ulceration of the gastrointestinal tract, allowing for erosion and invasion by the endogenous microorganisms. Two agents, bleomycin and methotrexate, are associated with skin lesions, which can predispose to bacteremia with staphylococci and other skin organisms. BCNU, ara-C, and daunomycin irritate veins, increasing the risk of phlebitis and subsequent bacteremia. Most chemotherapies cause bone marrow suppression and neutropenia in a dose-related fashion. Some of these drugs can also inhibit neutrophilic migration and chemotaxis. Regimens that include corticosteroids inhibit the bactericidal activity of neutrophils. Humoral immunity is altered by agents such as methotrexate, cyclophosphamide, and 6-mercaptopurine.

Other agents, such as interleukin- 2 and deferoxamine, are associated with specific types of infections. Interleukin-2 has been linked to increased infection, particularly with staphylococci. This is predominantly due to druginduced defects in neutrophil function. Deferoxamine is associated with increases in bacterial infections and zygomycosis, most likely due to the increased availability of free iron necessary for fungal growth [8]. Currently, deferoxamine is being used experimentally to treat neuroblastomas, and a case of Fusarium in a child receiving deferoxamine for this indication was recently reported [84]. 
Table 3. Chemotherapeutic agents that predispose to infection

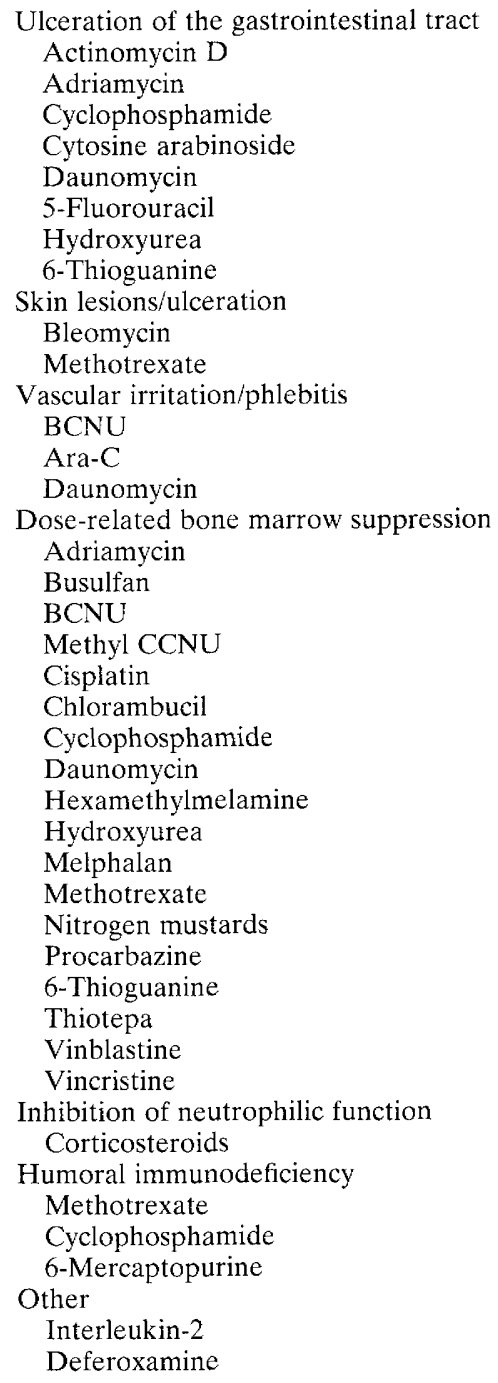

\subsection{Antibiotics}

Antibiotics used for both prophylaxis and treatment alter a patient's microflora and select for resistant organisms. Examples of this have been proven repeatedly in cancer patients. Trials of nonabsorbable antibiotics were previously used to decrease colonization of the alimentary canal. These trials were halted in part due to the emergence of resistant organisms [85-87]. 
The use of fluconazole for fungal prophylaxis in bone marrow transplant recipients has been associated with outbreaks of $C$. krusei infections [71,88]. The use of fluoroquinolones in neutropenic cancer patients is associated with an increase in infection with resistant staphylococci, streptococci, and anaerobes, as well as increased fluoroquinolone resistance in the gram-negative rods $[17,89]$. The total amount of ceftazidime, the duration of treatment, and the number of days of therapy with this agent have all been implicated in the emergence of vancomycin-resistant Enterococcus faecium bacteremia [90,91]. Although antibiotic use in cancer patients is essential in many situations, the emergence of resistant organisms can be directly linked to antibiotic selective pressure. These antibiotic-resistant organisms pose a major health threat to all patients, especially to those who are immunocompromised.

\subsection{Diagnostic and invasive procedures}

Diagnostic and invasive procedures are well-recognized factors predisposing to infection. Any procedure that breaks the natural protective barrier between the internal and external environment can allow bacteria or fungi to enter the bloodstream. Biopsies, bone marrow aspirations, endoscopy, and indwelling urinary catheters are but a few examples. Strict attention to sterile technique, when applicable, can decrease but cannot completely eliminate the infectious risk associated with these procedures.

\subsection{Central venous catheters}

Semipermanent centrally placed venous access devices, such as those developed by Broviac and Hickman, are commonly used in cancer patients to administer chemotherapy, blood products, antibiotics, and parenteral nutrition, and to obtain blood specimens for laboratory analyses. Infection is a common and potentially life-threatening complication of these vascular access devices. The most commonly isolated pathogens are staphylococci and streptococci, although infections with Bacillus spp., Corynebacterium spp., and yeast such as $C$. albicans are also frequently diagnosed [92,93]. The rapidly growing nontuberculous mycobacteria, $M$. chelonei and $M$. fortuitum, have also been associated with exit-site or tunnel infections around these intravascular catheters [94].

Almost all of these long-term intravenous devices become colonized within a few days of insertion; however, only $15-20 \%$ develop a clinically significant infection. On average, when correlated with the number of catheter days, the incidence of infection is approximately 1.37 episodes per 1000 patient days of long-term catheter use [95]. Data from Memorial Sloan-Kettering Cancer Center suggest that completely implanted ports (Port-A-Caths) are less prone to device-related infection than are intravenous catheters, probably due to the more frequent manipulation of the Hickman or Broviac-type catheters when not in use [92]. Data on peripherally inserted central catheters (PICCs) 
suggest that infection rates are lower than for the centrally placed venous catheters. One study of PICC lines in critical care patients found the incidence of infection to be $0.48 \%$ per 1000 catheter days [96]. However, PICC lines are more prone to certain insertion and maintenance problems, such as catheter fracture, phlebitis, and occlusion $[97,98]$.

\subsection{Blood transfusions and bone marrow infusions}

Nosocomially acquired infections from blood transfusions occur despite modern blood banking techniques designed to prevent this complication. Cancer patients, especially those with hematologic malignancies or those undergoing bone marrow transplantation, may require several transfusions during the course of their illness, and thus are at increased risk of transfusion-related infection.

Contamination of blood products can occur during processing and storage, but most commonly occurs through collection of blood from infected donors [99]. For an organism to cause an infection in a transfused patient, it must (1) be present in the donor's blood at the time of collection while producing few or no symptoms; (2) escape detection by current screening methods; (3) remain viable in citrated, refrigerated blood for prolonged periods of time; and (4) be of sufficient virulence and quantity to produce infection in the transfusion recipient [100].

Viruses are the most frequently encountered pathogens associated with blood transfusions. These include hepatitis viruses, human immunodeficiency virus, Epstein-Barr virus, and cytomegalovirus (CMV). Although most of these are detected by present screening procedures, CMV remains a significant risk for cancer patients.

Protozoal diseases, such as leischmaniasis, trypanosomiasis, Chagas' disease, and microfilarial infections, are acquired through transfusion in developing countries. An increased incidence of transfusion-related Chagas' disease has also been reported in the United States. Malaria is uncommon in the United States but does occur, especially in people who have returned from travel in endemic areas. Therefore, transfusion-related malaria remains a potential risk in this country [101-104]. Babesia microti, a tick-borne protozoan parasite, has been transmitted through transfusion along coastal regions of the northeastern United States. It can cause a life-threatening infection in immunocompromised, especially asplenic, patients [104,105].

The procedure of storing citrated blood at $4^{\circ} \mathrm{C}$ for prolonged periods has greatly reduced the risks of transfusion-transmitted bacterial infections. Although up to $6 \%$ of stored blood contains some form of bacterial contamination, most of these organisms are normal skin flora such as $S$. epidermidis and diptheroids, which do not cause significant infections in transfusion recipients. On the other hand, Pseudomonas fluorescens/putida and Yersinia enterocolitica can survive and multiply in cold storage. These organisms have been associated with life-threatening sepsis following blood transfusions 
$[106,107]$. Platelets are often stored at room temperature to enhance their post-transfusion function. Thus, bacterial infections are more likely to occur following platelet transfusions [108].

With increasing numbers of patients undergoing bone marrow transplantation, the transmission of infectious agents during bone marrow reinfusion needs to be considered. To minimize this risk, strict attention must be paid to the health status of the donor and to the procedures for processing and storing of specimens in the time between donation and transplantation.

\section{Infections related to underlying malignancies}

Infections in cancer patients are largely determined by the underlying malignancy and the treatments directed against it. Understanding the risk factors that predispose to infection and applying this knowledge to a specific clinical situation helps to logically guide diagnosis and therapy (Table 4).

\subsection{Acute leukemia and lymphoma}

Patients with acute leukemia and lymphoma who are neutropenic, either due to their underlying disease or to cytotoxic chemotherapy, are at risk for a different set of infections than those who are not neutropenic. Classically in neutropenic patients, gram-negative bacilli such as E. coli, Klebsiella spp., and $P$. aeruginosa cause the earliest infections. These usually occur within the first 2-3 weeks after the initiation of chemotherapy and are due to the rapid decrease in the neutrophil count. These infections are characterized by acute febrile episodes, which can progress to overwhelming sepsis if not treated promptly $[13,15,109-114]$.

During the 1980s however, investigators noted a relative decrease in the number of gram-negative bacteremias and a significant increase in infections caused by gram-positive aerobic bacteria, namely, staphylococci and streptococci. Several reasons for this observation have been postulated $[115,116]$. The use of both prophylactic and empiric antibiotic regimens targeting gram-negative bacteria diminishes recovery of gram-negative pathogens while selecting for gram-positive infections $[117,118]$. One example is the emergence of streptococcal infections in populations of patients receiving fluoroquinolones [119]. The use of intravascular catheters also increases the likelihood of infection with gram-positive bacteria, such as staphylococci, that colonize the skin [117]. Chemotherapeutic regimens that cause oral mucositis predispose to infection with bacteria that ordinarily colonize the oropharynx, namely, alpha-hemolytic streptococci. Although the mortality associated with gram-positive infections is less than that of gram-negative, the morbidity is significant. For example, alpha-hemolytic streptococci have been associated with cases of adult respiratory distress syndrome (ARDS) in patients receiving cytarabine [119]. Furthermore, patients who remain 
Table 4. Infections related to the underlying malignancy

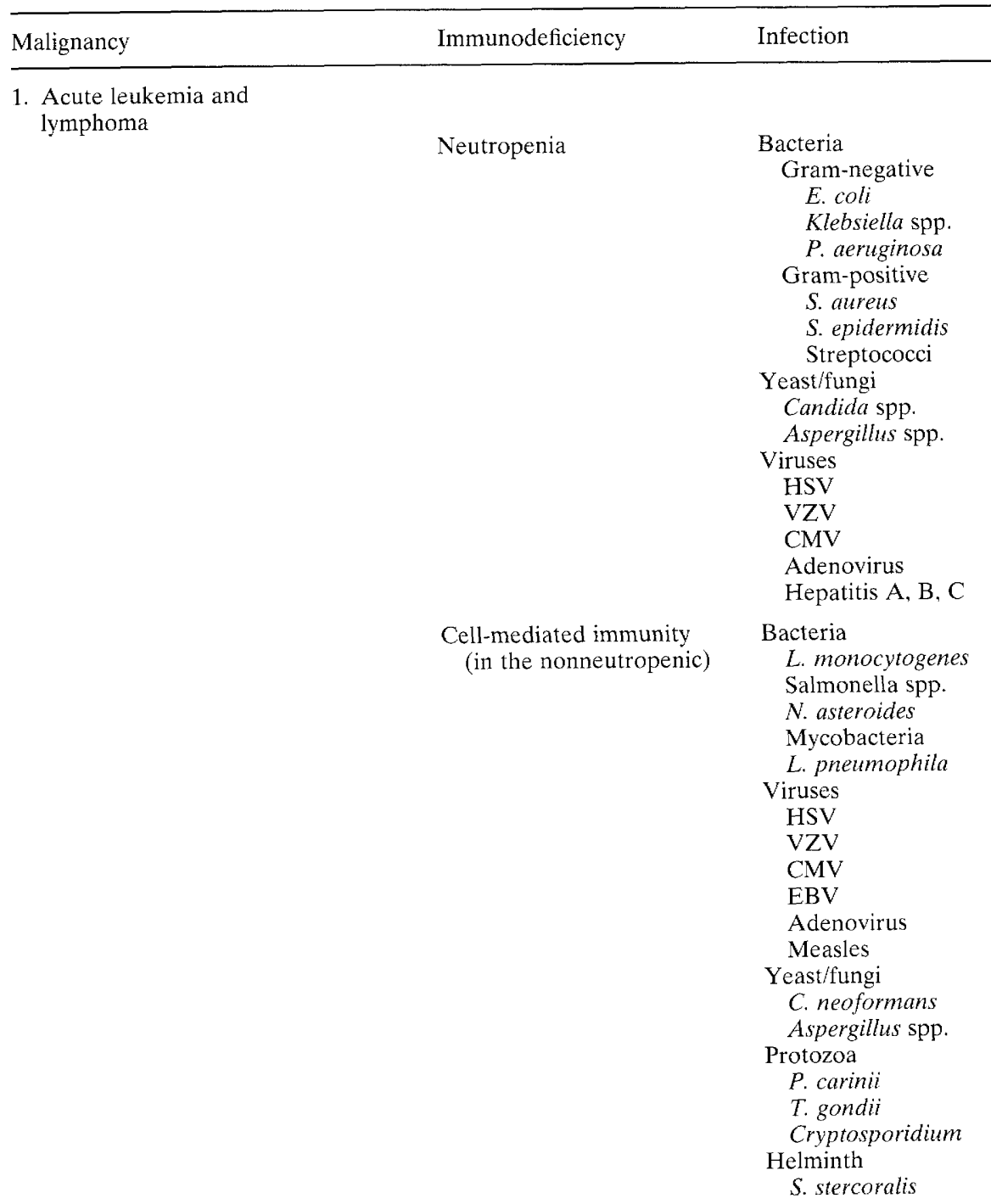

2. Chronic lymphocytic leukemia
Hypogammaglobulinemia
As the disease progresses: combination chemotherapy, with or without steroids, splenectomy, and occasionally radiation therapy predispose to further opportunistic infections

S. pneumoniae H. influenzae

E. coli 
Table 4. (continued)

\begin{tabular}{lcl}
\hline Malignancy & Immunodeficiency & Infection \\
\hline 3. Multiple myeloma & Humoral & \\
& immunodeficiency; & S. pneumoniae \\
& H. influenzae \\
& Nemplement deficiency & N. meningitidis \\
& disease & Gram-negative bacilli \\
& Cell-mediated & \\
immunodeficiency & & Bacteria \\
& Salmonella spp. \\
& L. monocytogenes \\
& M. kansasii \\
& & MAC \\
& & M. chelonei \\
& & Yeast \\
& Candida spp. \\
& C. neoformans \\
& & Viruses \\
& HSV
\end{tabular}

5. Solid organ tumors

Neutropenia

Disruption of anatomic
barriers

Mechanical obstructions

CNS tumors
Loss of gag reflex Impaired micturition Impaired mobility
Gram-negative bacilli

\author{
Skin \\ Staphylococci \\ Streptococci \\ Oral \\ cavity/nasopharynx \\ Anaerobes \\ Streptococci \\ H. influenzae \\ GI tract \\ Enterobacteriaceae \\ Fungi \\ Female gential tract \\ Enterobacteriaceae \\ Anaerobic GNB \\ Enterococci \\ Clostridium spp.
}

Biliary, urinary, and respiratory tract infection, and vascular obstruction

Aspiration pneumonia Recurrent UTIs

Decubitus ulcers with or without osteomyelitis

$\mathrm{CMV}=$ cytomegalovirus; $\mathrm{EBV}=$ Ebstein-Barr virus; $\mathrm{GNB}=$ gram-negative bacteria; $\mathrm{HSV}=$ herpes simplex virus; $\mathrm{MAC}=$ Mycobacterium avium complex; UTIs = urinary tract infections; $\mathrm{VZV}=$ varicella zoster virus. 
neutropenic for prolonged periods of time are more likely to develop infections with multidrug-resistant bacteria such as Corynebacterium jeikeium, Serratia spp., Enterobacter spp., Acinetobacter spp., Pseudomonas cepacia, and Stenotrophomonas (Xanthomonas) maltophilia. These emerge as a consequence of protracted courses of broad-spectrum antibiotics [111,112,120].

Because neutrophils play a major role in controlling infections due to Candida and Aspergillus, invasive fungal infections are also frequently encountered in neutropenic patients [121-126]. Autopsy series have documented invasive fungal infections in $10-40 \%$ of patients with underlying hematologic malignancies (see Chapter 6) [27,127-129]. Besides prolonged granulocytopenia, extended hospital stays, previous antibiotics, corticosteroids, central venous catheters, and total parenteral nutrition are risk factors for fungemia. In addition, many other uncommon fungi have been reported to cause infection in this patient population, as is discussed later in this chapter.

Viruses commonly infect neutropenic hosts (see Chapter 7). Reactivation of HSV is by far the most common viral infection encountered. VZV, CMV, adenovirus, and the viral hepatitides have also been reported in the neutropenic patient with acute leukemia or lymphoma [130-137].

\subsection{Nonneutropenic patient}

Leukemia or lymphoma patients who are not neutropenic demonstrate deficiencies in cell-mediated immunity, due either to their underlying disease or to the treatment regimens they receive. This cellular immunodeficiency predisposes them to infections with a variety of intracellular organisms. In addition, many of them have undergone splenectomy, putting them at risk for bacteremia with the encapsulated bacteria. Bacterial infections in this subgroup of patients are most commonly caused by Listeria monocytogenes, Legionella pneumophilia, Salmonella spp., Mycobacterium tuberculosis, the nontuberculous mycobacteria, and Nocardia spp. [10]. Patients who have undergone splenectomy are at risk for Streptococcus pneumoniae, $N$. meningitidis, and $H$. influenzae [81]. Fungal infections other than Cryptococcus and occasionally Aspergillus are uncommon [138]. Protozoal infections, on the other hand, are much more common in the nonneutropenic patient. Infections with Pneumocystis carinii, Toxoplasma gondii, Strongyloides stercoralis, and Cryptosporidium have all been reported [42-44]. Viruses such as HSV, VZV, and CMV are all encountered in these patients [10], and cases of measles have been reported in nonneutropenic children with acute lymphocytic leukemia [136].

\subsection{Chronic lymphocytic leukemia}

Chronic lymphocytic leukemia (CLL) represents a clonal expansion of neoplastic B lymphocytes in more than $95 \%$ of cases [139]. These mature- 
appearing B lymphocytes are found in the peripheral blood. They also infiltrate the bone marrow, spleen, and lymph nodes. Much of the gamma globulin produced by patients with CLL is nonfunctional, leading to defects in humoral immunity. This humoral immunodeficiency worsens as the disease progresses and does not revert after chemotherapy. CLL patients are at risk for infection with encapsulated pyogenic bacteria such as $S$. pneumoniae and $H$. influenzae, as well as $E$. coli. As the malignancy progresses, treatment modalities may include corticosteroids, combination chemotherapy, splenectomy, and occasionally radiation therapy for control of localized disease, all of which increase the risk of opportunistic infections [62].

\subsection{Multiple myeloma}

Like CLL, patients with multiple myeloma (MM) classically present with defects in humoral immunity. MM patients are hypogammaglobulinemic, producing normal immunoglobulins at only $10 \%$ the normal rate. Therefore, they are predisposed to infections with the encapsulated bacteria such as Streptococcus pneumoniae, $H$. influenzae, and $N$. meningitidis $[48,49]$. As disease progresses, the malignant plasma cells proliferate within the bone marrow to such an extent that the marrow is unable to produce adequate numbers of neutrophils. Therefore, patients with advanced disease may become neutropenic, increasing their risk of gram-negative bacterial infections [50].

\subsection{Hairy cell leukemia}

This chronic B-cell lymphoproliferative disorder presents with cytopenias in the majority of patients. In particular, patients have monocytopenia, granulocytopenia, and defective T-cell function. This results in a cellular immunodeficiency and predisposes to a variety of infections. As in other patients, the neutropenia predisposes to gram-negative bacterial infections. Defects of cell-mediated monocyte/macrophage and T-cell function predispose to other bacterial infections with organisms such as Salmonella and Listeria; fungal infections with Candida and Cryptococcus; viral infections with HSV and CMV; and nontuberculous mycobacterial infections with $M$. kansasil, $M$. avium complex, and $M$. chelonei $[140,141]$. In one review from the University of Chicago, five of nine hairy cell leukemia patients with nontuberculous mycobacterial infections had disseminated disease at presentation [142].

\subsection{Solid organ tumors}

Patients with solid organ tumors do not have the same risk of infection as patients with underlying hematologic malignancies. This is largely because the standard chemotherapeutic regimens used to treat these malignancies do not usually result in either long-term or profound levels of neutropenia. Excep- 
tions include patients with small cell carcinoma of the lung, testicular carcinoma, and some sarcomas. Aggressive chemotherapeutic regimens used to treat these malignancies may result in periods of neutropenia for 7-10 days or more [62]. Likewise, malignancies such as metastatic carcinoma of the breast, prostate, lung, adrenal, thyroid, and kidney have a propensity to infiltrate the bone marrow and can result in neutropenia in the advanced stages of disease. Patients with tumors of the central nervous system, either primary or metastatic, are at risk for a unique set of infections based on the associated neurologic deficit. An impaired gag reflex can lead to aspiration pneumonia, impaired micturition to recurrent urinary tract infections, and impaired mobility to decubitus ulcers with or without osteomyelitis.

Any solid organ tumor that invades and disrupts anatomic barriers may predispose to infection. These include tumors of the skin, oral cavity, nasopharynx, gastrointestinal, respiratory, and urogenital tracts. These malignancies and their associated pathogens were discussed previously.

\subsection{Bone marrow transplantation}

The patient who has undergone bone marrow transplantation serves as an excellent example of how various host immunodeficiencies predispose to specific infectious pathogens. From the standpoint of infection, the posttransplant course can be divided into three separate time periods (Table 5). The first 20-30 days following transplantation, the pre-engraftment period, is characterized by a precipitous loss of circulating granulocytes. Also during this time, many of the anatomic barriers have been disrupted, such as the oral and gastrointestinal mucosa, resulting in a predominance of bacterial and fungal infections. For the most part, these organisms include staphylococci, streptococci [143], Corynebacterium, Propionibacterium, E. coli, Klebsiella, and Pseudomonas, followed by Candida and Aspergillus as prior antibiotic therapy shifts the local flora $[144,145]$. Reactivation of HSV is also common during this stage. By 20-30 days post-transplant, most patients have recovered their granulocytes.

The second period, early postengraftment, encompasses the time from recovery of circulating granulocytes through day 100 . As the neutropenia resolves, the patient's clinical condition improves rapidly; however, neutrophil function, especially chemotaxis, is not entirely normal. The recovery of cellmediated immunity is also delayed. The proportion and sometimes the absolute number of $\mathrm{T}$ cells may be abnormal for prolonged periods, occasionally for several years after transplantation. Therefore, bacterial and fungal infections may continue to occur, especially during the early part of the second stage. However, viral and protozoal infections increase in incidence during this stage [146,147]. A diffuse interstitial pneumonia of unknown etiology has also been reported during this period [148,149]. The pathogens to expect 30-100 days post-transplant include CMV, Pneumocystis carinii, toxoplasmosis, and cryptosporidiosis. 
Table 5. Time course for infection in bone marrow transplant recipients

\begin{tabular}{|c|c|c|}
\hline Day post-transplantation & Immunodeficiency & Common pathogens \\
\hline \multicolumn{3}{|l|}{ Pre-engraftment } \\
\hline $0-30$ & $\begin{array}{l}\text { Granulocytopenia and disrupted } \\
\text { anatomic barriers }\end{array}$ & $\begin{array}{l}\text { Staphylococci } \\
\text { Streptococci } \\
\text { Corynebacterium } \mathrm{spp} \text {. } \\
\text { Propionobacterium } \mathrm{spp} . \\
\text { E. coli } \\
\text { Klebsiella } \mathrm{spp} . \\
\text { P. aeruginosa } \\
\text { Candida } \text { spp. } \\
\text { Aspergillus } \text { spp. } \\
\text { Reactivation of } \mathrm{HSV}\end{array}$ \\
\hline \multicolumn{3}{|l|}{ Early post-engraftment } \\
\hline $30-100$ & $\begin{array}{l}\text { Delayed recovery of neutrophil } \\
\text { function, esp. chemotaxis }\end{array}$ & $\begin{array}{l}\text { Bacterial/fungal infections may } \\
\text { continue to occur as in the } \\
\text { pre-engraftment stage }\end{array}$ \\
\hline & Cell-mediated immunodeficiency & $\begin{array}{l}\text { CMV, PCP, T. gondii } \\
\text { Cryptosporidiosis, diffuse } \\
\text { interstitial pneumonitis } \\
\text { (unclear etiology) }\end{array}$ \\
\hline \multicolumn{3}{|l|}{ Late post-engraftment } \\
\hline$>100$ & $\begin{array}{l}\text { Hypogammaglobulinemia; } \\
\text { functional asplenia with } \\
\text { decreased IgG and IgM levels } \\
\text { for } 6-8 \text { months; decreased IgA } \\
\text { levels for } 1 \text { year or longer } \\
\text { If GVHD develops, immunologic } \\
\text { function recovers more slowly } \\
\text { and patients are susceptible to } \\
\text { opportunistic infections for } \\
\text { longer periods of time }\end{array}$ & $\begin{array}{l}\text { VZV; } S \text {. pneumoniae; chronic } \\
\text { viral hepatitides, such as } \\
\text { HCV acquired in the early } \\
\text { pre-engraftment period }\end{array}$ \\
\hline
\end{tabular}

$\mathrm{HCV}=$ hepatitis $\mathrm{C}$ virus; GVHD = graft-versus-host disease; $\mathrm{CMV}=$ cytomegalovirus; $\mathrm{HSV}=$ herpes simplex virus; $\mathrm{PCP}=$ Pneumocystis carinii pneumonia; VZV $=$ varicella zoster virus.

The third time period, after day 100 , is the late postengraftment period. It is characterized by low levels of circulating immunoglobulins. IgG and IgM levels may remain depressed for 6-8 months or longer, and IgA levels may remain depressed for at least 1 year. Patients who develop chronic GVHD recover their immunologic function more slowly and are susceptible to opportunistic infections for longer periods of time. Characteristic infections occurring after day 100 include VZV and bacteremic pneumococcal infection. Nearly $40 \%$ of bone marrow transplant patients develop VZV infection, and the median time of onset is 5 months after transplantation. The incidence of pneumococcal bacteremia relates to chronic GVHD-induced hyposplenism with loss of opsonizing antibodies to the encapsulated gram-positive organisms. After day 100, infection with hepatitis $\mathrm{C}$ virus that may have been acquired through transfusions during the first 3 weeks after transplantation can become clinically manifest [150-152]. 


\section{Emerging pathogens}

All clinicians caring for cancer patients must be aware of the emerging or newly recognized pathogens that are increasingly affecting this patient population. Infections with multidrug-resistant organisms are becoming more and more common. Liberal use of broad-spectrum antibiotics, prophylactic antimicrobial therapy, and complacency in prescribing techniques underlies the development of these resistant organisms $[89,153,154]$. Furthermore, organisms that were previously considered commensal or nonpathogenic have been shown to cause serious infections in these immunocompromised hosts. An awareness of emerging pathogens is essential for the diagnosis and management of patients with underlying malignancies (Table 6).

\subsection{Bacteria}

5.1.1 Aerobic gram-positive bacteria. Enterococci have emerged as important nosocomial pathogens. Estimates suggest that enterococci play a causal role in $12 \%$ of all hospital-acquired infections. Two species of enterococci, Enterococcus faecalis and Enterococcus faecium, account for the majority of clinical infections [90]. Vancomycin resistance among enterococci was first described clinically in 1988 [155] and has since become a global problem. Indeed, many strains are not only vancomycin resistant but are multidrugresistant, and some multidrug-resistant strains of $E$. faecium are untreatable. Risk factors for invasive infection in oncology patients include the total amount and duration of antibiotic treatment, and the number of days of ceftazidime use [91]. Montecalvo and colleagues described an outbreak of multidrug-resistant $E$. faecium bacteremia on an oncology unit. Of the five patients who had multiple positive blood cultures, four died [156]. A report by Noskin and associates suggests that once patients are colonized with vancomycin-resistant enterococci (VRE), this colonization can last indefinitely and can later lead to invasive infection [157]. Although several antibiotics and antimicrobial combinations have been tried, standard therapeutic regimens have not been defined. Therefore, therapy may require unconventional or investigational agents [158].

Streptococci have recently received renewed interest as an important pathogen in the neutropenic host $[56,159,160]$. Streptococcus mitis, a viridans streptococci, has been associated with sepsis and ARDS in leukemic patients. The emergence of infection with both Streptococcus pneumoniae and the viridans streptococci has been demonstrated in cancer patients receiving fluoroquinolone prophylaxis. Fluoroquinolones, such as ciprofloxacin, have little activity against these organisms, giving them a selective advantage [161]. Streptococcus pneumoniae are becoming increasingly resistant to penicillin, and many strains are multidrug-resistant. Researchers at Northwestern University in Chicago have reported that in $1996,35 \%$ of their strains possessed intermediate resistance to penicillin while $11 \%$ were highly penicillin resistant 
[162]. Outbreaks of penicillin-resistant pneumococci on oncology wards have recently been reported. Because of this, when life-threatening infections with pneumococci are encountered or suspected, many centers are using either vancomycin or ceftriaxone as first-line therapy.

Leuconostoc species, previously regarded as a commensal, have been reported to cause bacteremia in patients with intravascular catheters. These organisms can be confused microbiologically with enterococci, viridans

Table 6. Emerging pathogens

\begin{tabular}{|c|c|}
\hline Pathogen & Comments \\
\hline \multicolumn{2}{|l|}{ Bacteria } \\
\hline \multicolumn{2}{|c|}{ Aerobic gram-positive bacteria } \\
\hline VRE & $\begin{array}{l}\text { No standard therapy; may require unconventional or } \\
\text { investigational agents }\end{array}$ \\
\hline Streptococci & $\begin{array}{l}\text { Increased incidence noted in patients receiving } \\
\text { fluoroquinolone prophylaxis }\end{array}$ \\
\hline Viridans streptococci & Associated with sepsis and ARDS in leukemic patients \\
\hline S. pneumoniae & $\begin{array}{l}\text { Increasingly penicillin and multidrug-resistant; empiric } \\
\text { vancomycin or ceftriaxone used for life-threatening } \\
\text { infections }\end{array}$ \\
\hline Leuconostoc spp. & $\begin{array}{l}\text { Inherently resistant to vancomycin; variably sensitive } \\
\text { to penicillin and first-generation cephalosporins }\end{array}$ \\
\hline S. mucilaginosus & $\begin{array}{l}\text { Mucositis is a risk factor, treat with penicillin or } \\
\text { vancomycin }\end{array}$ \\
\hline C. jeikeium & $\begin{array}{l}\text { Multiply drug resistant; remains vancomycin } \\
\text { susceptible }\end{array}$ \\
\hline B. cereus & $\begin{array}{l}\beta \text {-lactam antibiotics rarely effective in vitro; empiric } \\
\text { therapy should consist of vancomycin or clindamycin } \\
\text { with or without gentamicin }\end{array}$ \\
\hline R. equi & $\begin{array}{l}61 \% \text { survival with antibiotics alone; } 75 \% \text { for } \\
\text { antibiotics plus surgical resection }\end{array}$ \\
\hline
\end{tabular}

Aerobic gram-negative bacteria S. maltophilia

GNB-containing ESBLs

P. cepacia, M. extorquens, $A$. radiobacter, $O$. anthropi, A. xylosoxidans

A. putrefaciens

Capnocytophagia Anaerobic bacteria

C. septicum

C. tertium

F. nucleatum, L. buccalis

Mycobacteria

M. tuberculosis

M. avium complex

M. fortuitum, M. chelonae M. haemophilum

Nortoriously multidrug resistant; usually resistant to all aminoglycosides

Plasmid-mediated resistance to many penicillins/thirdgeneration cephalosporins

Associated with catheter-related bacteremias

Fulminant syndrome of overwhelming sepsis and DIC in immunocompromised hosts

Risk factors are mucositis and neutropenia

Necrotizing enterocolitis

Perirectal cellulitis

Part of the normal oral flora; mucositis and pharyngitis are risk factors

Combined medical and surgical approaches may be necessary in multidrug-resistant $\mathrm{M}$. tuberculosis

Accounts for $27 \%$ of nontuberculous mycobacteria in cancer patients

Most commonly cause catheter infections

Optimal treatment regimens not well defined 
Table 6. (continued)

\begin{tabular}{|c|c|}
\hline Pathogen & Comments \\
\hline \multicolumn{2}{|l|}{ Viruses } \\
\hline VZV, HSV & Treatment with foscarnet in acyclovir-resistant strains \\
\hline CMV & Treatment with ganciclovir or foscarnet \\
\hline HTLV-I & Associated with T-cell NHL \\
\hline HTLV-II & Associated with hairy cell leukemia \\
\hline HIV & Associated with B-cell NHL \\
\hline KSHV (HHV-8) & Herpes virus associated with Kaposi's sarcoma \\
\hline \multicolumn{2}{|r|}{ 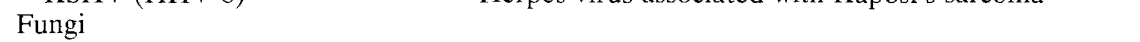 } \\
\hline Candida spp. & $\begin{array}{l}\text { C. albicans still predominates, although non-albicans } \\
\text { species are increasing }\end{array}$ \\
\hline Aspergillus spp. & $\begin{array}{l}\text { At some institutions, A. flavus is now more common } \\
\text { than } \text { A. fumigatus }\end{array}$ \\
\hline $\begin{array}{l}\text { Fusarium spp., } \\
\text { Scopulariopsis spp., } \\
\text { P. boydii }\end{array}$ & $\begin{array}{l}\text { Severe, often fatal infection in neutropenic hosts; } \\
\text { recovery of neutrophil count is required for a } \\
\text { successful outcome }\end{array}$ \\
\hline $\begin{array}{l}\text { Curvularia spp., } \\
\text { Bipolaris spp., } \\
\text { Exserohilum spp., } \\
\text { Alternaria spp., } \\
\text { Aspergillus spp. }\end{array}$ & Fungal sinusitis, which may lead to brain abscess \\
\hline T. beigelii & $\begin{array}{l}\text { Disseminated disease may occur; treatment is difficult } \\
\text { and relapse is common }\end{array}$ \\
\hline B. capitatus & Severe, disseminated infection in neutropenic patients \\
\hline M. furfur & $\begin{array}{l}\text { Catheter-related sepsis in patients receiving parenteral } \\
\text { lipids; sensitive to amphotericin B and the azoles; } \\
\text { catheter removal and discontinuation of lipids }\end{array}$ \\
\hline $\begin{array}{l}\text { E. jeanselmei, E. pisciphila, } \\
\text { E. spinifera, S. inflatum }\end{array}$ & $\begin{array}{l}\text { Wide, deep surgical debridement or cryosurgery in } \\
\text { early-stage disease; medical therapy has been } \\
\text { disappointing }\end{array}$ \\
\hline $\begin{array}{l}\text { R. rubra, H. anomala, } \\
\text { G. candidum, S. cereviseae, } \\
\text { Drechslera spp., P. parasitica, } \\
\text { Acremonium spp., P. farinosa }\end{array}$ & All have been associated with catheter infections \\
\hline P. carinii & $\begin{array}{l}\text { Increased incidence in patients with brain tumors } \\
\text { attributed to intensive chemotherapy and high } \\
\text { doses of corticosteroids }\end{array}$ \\
\hline \multicolumn{2}{|l|}{ Protozoa and parasites } \\
\hline T. gondii & $\begin{array}{l}\text { Primary treatment should be followed by maintenance } \\
\text { therapy to prevent relapse in chronically } \\
\text { immunosuppressed patients }\end{array}$ \\
\hline Cryptosporidium & No reliable palliative or curative therapy exists \\
\hline S. stercoralis & $\begin{array}{l}\text { Very high mortality in immunocompromised hosts; } \\
\text { thiabendazole is the only effective therapy }\end{array}$ \\
\hline \multicolumn{2}{|r|}{ (2) } \\
\hline B. quintana, $B$. henselae & $\begin{array}{l}\text { Causative agents of bacillary angiomatosis and } \\
\text { bacillary peliosis; doxycycline or erythromycin is the } \\
\text { treatment of choice }\end{array}$ \\
\hline P. wickerhamii & $\begin{array}{l}\text { Surgical debridement plus amphotericin B have been } \\
\text { used successfully }\end{array}$ \\
\hline
\end{tabular}

ARDS $=$ adult respiratory distress syndrome; $\mathrm{CMV}=$ cytomegalovirus; $\mathrm{DIC}=$ disseminated intravascular coagulation; ESBLs = extended-spectrum beta-lactamases; GNB = gram-negative bacteria; HHV-8 $=$ human herpes virus $8 ; \mathrm{HSV}=$ herpes simplex virus; HTLV $=$ human T-cell lymphotropic virus; KSHV = Kaposi's sarcoma herpes virus; NHL = non-Hodgkin's lymphoma; $\mathrm{VRE}=$ vancomycin-resistant enterococci; $\mathrm{VZV}=$ varicella zoster virus. 
streptococci, or lactobacillus. It is important to differentiate Leuconostoc because this organism is inherently vancomycin-resistant and only variably sensitive to penicillins and the first-generation cephalosporins [163].

Stomatococcus mucilaginosus is a slime-producing, gram-positive coccus that is found in the normal oral flora of humans [164]. McWhinney and coworkers recovered $S$. mucilaginosus from eight febrile, neutropenic patients. Seven of these patients had bacteremia and one had positive cerebrospinal fluid cultures resulting in a fatal meningitis. Four of these patients had proven infections with this organism, and all eight had mucositis attributable to chemotherapy. All but one of these isolates was sensitive to penicillin, and all were sensitive to vancomycin [165].

Prior to 1976, Corynebacterium spp., bacteria normally abundant on the skin and mucous membranes, rarely caused infections and were susceptible to most antibiotics. However, in 1976, four cases of sepsis at the National Institutes of Health caused by Corynebacterium jeikeium were reported [166]. This organism is highly antibiotic-resistant but is vancomycin susceptible. Since then $C$. jeikeium has been increasingly recognized to cause intravascular catheter-associated bacteremias in neutropenic patients with underlying hematologic malignancies [167]. It has also caused meningitis and transverse myelitis in one neutropenic patient [168].

Cases of primary cutaneous Bacillus cereus infections have occurred in neutropenic patients with cancer or aplastic anemia. In these patients, the lesions were vesicular or pustular, only occurred on the limbs, and arose in the spring or summer. They all responded to antibiotic therapy [169]. B. cereus can also cause more severe clinical syndromes, such as necrotizing fasciitis, pneumonitis, and meningitis. In vitro data suggest that $\beta$-lactam antibiotics are rarely effective; therefore, empiric therapy for a suspected infection with Bacillus spp. should consist of vancomycin or clindamycin with or without an aminoglycoside [170].

Rhodococcus equi is an uncommon pathogen that has been reported to cause infection in patients with impaired cellular immunity. HIV infection is the most common predisposing risk factor; however, infection in patients with other forms of cellular immunodeficiency have also been described. $R$. equi is most frequently associated with a cavitary pneumonia, which may mimic a fungal infection or tuberculosis. In a study by Harvey and Sunstrum, the survival rate for patients receiving antibiotics alone was $61 \%$ compared with $75 \%$ for those receiving both antibiotics and surgical resection [171].

5.1.2 Aerobic gram-negative bacteria. Although the overall incidence of gram-negative infections is decreasing in cancer patients, the gram-negative aerobic bacteria still cause significant morbidity and mortality. The use of broad-spectrum prophylactic and empiric antibiotics targeting the gramnegative bacteria has also led to increased antimicrobial resistance among these organisms. 
Stenotrophomonas (Xanthomonas) maltophilia is an organism that is frequently isolated from the environment, particularly from water supplies. Both colonization and infection among immunocompromised patients is increasing, especially in those receiving broad-spectrum antibiotics, particularly imipenam. S. maltophilia causes pneumonia, urinary tract infections, bacteremia, and wound infections in debilitated patients and is notoriously multidrug-resistant, making treatment difficult [172].

Enterobacteriaceae are also becoming more drug resistant. For example, a study by the International Antimicrobial Therapy Cooperative Group (IATCG) of the EORTC between 1983 and 1993 showed that the number of patients receiving fluoroquinolones had increased from $1.4 \%$ to $45 \%$. During this same period, E. coli resistance to these drugs increased from $0 \%$ between 1983 and 1990 to 27\% between 1991 and 1993 [17]. Certain Enterobacteriaceae, namely, E. coli and Klebsiella spp., have developed extended-spectrum beta-lactamases (ESBLs), enzymes that render them resistant to many penicillins and cephalosporins, particularly the third-generation cephalosporins. Although first- and second-generation cephalosporins may appear susceptible in vitro, clinical failures have been observed when these antibiotics are used. Therefore, imipenem, meropenem, or possibly a $\beta$ lactam/ $\beta$-lactamase inhibitor combination such as piperacillin/tazobactam is now the treatment of choice for patients who develop life-threatening infections with these organisms. This antibiotic resistance is plasmid mediated and thus can be spread from patient to patient, leading to nosocomial outbreaks [173-175]. Therefore, for patients infected or colonized with bacteria expressing ESBLs, contact isolation is appropriate.

Several unusual gram-negative pathogens have been associated with catheter-related bacteremia in cancer patients. An outbreak of Pseudomonas cepacia occurred on an oncology ward related to a contaminated heparin solution that was used to flush central venous catheters [176]. Methylobacterium extorquens bacteremia occurred in three acute leukemics, two of whom had undergone bone marrow transplantation and one who was receiving consolidation chemotherapy [177]. Catheter-associated bacteremia has also been reported with Agrobacterium radiobacter. This organism has also been associated with peritonitis, urinary tract infection, and endocarditis [178]. The first case of Ochrobactrum anthropi infection was reported in a 3year-old girl undergoing chemotherapy for retinoblastoma [179]. The experience with Achromobacter xylosoxidans bacteremia at M. D. Anderson Cancer Center from 1983 to 1988 has been reviewed. During this period, 10 cancer patients had positive blood cultures for this organism. In four, the infection was believed to be catheter related. An additional four had associated gastrointestinal pathology, and in the remaining two the predisposing factor could not be determined. Interestingly, neutropenia did not appear to be a risk factor [180].

Alteromonas (Pseudomonas) putrefaciens is an unusual organism that causes two distinct syndromes of bacteremic infection. One syndrome is 
associated with chronic lower extremity infection, is mild, and responds to antimicrobial therapy. The second, more fulminant syndrome is associated with severe underlying illnesses such as liver disease and malignancy. These patients are more likely to experience overwhelming sepsis and disseminated intravascular coagulation [181].

Capnocytophagia is a facultative anaerobe that constitutes part of the normal oral flora and is an unusual cause of systemic infection. Capnocytophagia bacteremia has been reported following autologous bone marrow transplantation for Hodgkin's disease. Infection followed pretreatment conditioning that was associated with severe oral mucositis and neutropenia [182].

5.1.3 Anaerobic bacteria. Traditionally, anaerobes have accounted for relatively few primary infections in cancer patients, except as part of mixed infections, such as necrotizing gingivitis, perianal cellulitis, or perirectal abscesses. However, recently, a few anaerobes have been recognized as important pathogens in these immunocompromised hosts. Two species of Clostridium, C. septicum and C. tertium, can cause significant infections in cancer patients. C. septicum has been known to cause necrotizing enterocolitis, and $C$. tertium has been isolated in neutropenic patients with perirectal cellulitis or another presumed gastrointestinal tract source [183,184]. Fusobacterium nucleatum was recovered from a leukemic patient with ulcerative pharyngitis and nodular pulmonary infiltrates suggestive of septic emboli $[185,186]$. Leptotrichia buccalis, part of the normal oral flora, has caused bacteremia in neutropenic patients whose only predisposing factor was mucositis [187].

5.1.4 Mycobacteria. Strains of Mycobacterium tuberculosis resistant to isoniazid and many other first-line agents have recently emerged. When infected with tuberculosis, the immunocompromised cancer patient is at increased risk for disseminated or miliary disease. The second-line agents that must be used, in many instances, are less effective; thus, combined medical and surgical approaches may be necessary in these patients.

Mycobacterium avium complex (MAC) is most commonly seen in AIDS patients but has also been reported in patients with underlying malignancies. MAC accounts for $27 \%$ of nontuberculous mycobacterial infections in cancer patients, especially patients with lung cancer. The most common clinical presentation is pulmonary disease; however, dissemination can occur [188].

$M$. fortuitum and $M$. chelonae, two rapidly growing strains of mycobacteria, are known to cause catheter-related infections. They cause disseminated disease less commonly than MAC, but often result in cellulitis, skin abscesses, or subcutaneous nodules. Treatment of the catheter infections requires antimicrobial therapy, catheter removal, and surgical excision if tunnel infection is present. For other skin and soft tissue infections, a combination of antimicrobial therapy and surgical debridement may be required $[189,190]$. 
Reports of M. haemophilum infection are increasing in lymphoma patients, bone marrow and renal transplant patients, and AIDS patients. Infection with this mycobacteria most commonly presents as cutaneous ulcerations, joint effusions, or osteomyelitis. Optimal treatment regimens are not well defined [191].

\subsection{Viruses}

Varicella-zoster virus, HSV, and CMV are well-known pathogens in cancer patients. However, prophylactic use of acyclovir and ganciclovir has led to both acyclovir and ganciclovir-resistant strains, which must then be treated with foscarnet [192]. Recently, cidofivir became available for therapy of CMV retinitis in AIDS patients [193,194].

Retroviruses have been increasingly recognized as important pathogens in cancer patients over the past decade. Human T-cell leukemia virus-I (HTLV-I) is associated with adult T-cell non-Hodgkin's lymphoma, HTLV-II with hairy cell leukemia, and HIV with adult B-cell non-Hodgkin's lymphoma.

Recently, a member of the gamma-herpesvirus family, referred to as Kaposi's sarcoma-associated herpesvirus (KSHV) or human herpesvirus 8 (HHV-8), has been associated with four types of Kaposi's sarcoma: classic KS, AIDS-associated KS, post-transplantation KS, and KS that occurs in endemic areas for the disease. It has also been associated with body-cavity-based lymphomas $[195,196]$.

\subsection{Fungi}

Candida spp. and Aspergillus spp. are the most common fungal infections in immunocompromised cancer patients, and recently several important trends have been noted. The incidence of nosocomial candidal bacteremia rose sharply in the late 1980s and early 1990s. At some institutions, Candida bacteremia now surpasses that of the Enterobacteriaceae, Pseudomonas spp., and Enterococcus spp. [197]. Candida albicans is still the most common species, accounting for more than half of fungal isolates from cancer patients, although the incidence of non-albicans species is increasing. Among these are C. tropicalis, C. parapsilosis, C. krusei, and C. (Torulopsis) glabrata [198,199]. Central venous catheters, total parenteral nutrition, and the increasing use of azoles for antifungal prophylaxis are some of the presumed mechanisms thought to account for this rising trend. Of the Aspergillus species, Aspergillus fumigatus is the most commonly isolated species to cause invasive disease. However, at some institutions, A. flavus has supplanted A. fumigatus as the most common cause of aspergillosis [200].

Many fungi are ubiquitous in nature and were thought, until recently, to be commensal or nonpathogenic. Several of these have now been proven to cause serious infections in immunocompromised cancer patients. Fusarium spp., Scopulariopsis spp., and Pseudallescheria boydii, members of the 
hyalohyphomycoses group, are important pathogens. Fusarium causes severe, often fatal, infections in neutropenic patients, particularly those who have undergone bone marrow transplantation. Fusarium is highly resistant to conventional antifungal drugs, and rising neutrophil counts are required for a successful response. Subsequent neutropenic episodes are associated with a high incidence of recurrence [201,202]. Scopulariopsis spp. and $P$. boydii have likewise been shown to cause serious disseminated disease in these patients [200].

Among the phaeohyphomycoses, Curvularia spp., Bipolaris spp., Exserohilum spp., and Alternaria spp. are known pathogens. These darkwalled molds are responsible for allergic fungal sinusitis. Patients may present with an indolent onset of sinus pain or painless proptosis. These infections can extend from the ethmoid or frontal sinuses into the frontal lobe causing brain abscesses. Differentiation of these fungi from Aspergillus is important. Other clinical syndromes, such as subcutaneous abscesses, cutaneous granuloma, disseminated disease, pneumonitis, prosthetic valve endocarditis, osteomyelitis, and septic arthritis, have been reported [203].

Trichosporon beigelii ( $T$. cutaneum) can be part of the normal human flora. Patients with leukemia or bone marrow aplasia may develop disseminated trichosporonosis. In patients with fungemia due to $T$. beigelli, multiple red papular skin lesions may develop. An infection of hair shafts, known as white piedra, has also been described. Treatment of these infections is difficult and relapse is common [204-206].

Blastoschizomyces capitatus (Trichosporon capitatum) has caused severe, disseminated infection in at least 25 patients, 19 of whom were neutropenic. Six of these patients had papulonecrotic skin lesions similar to those seen in disseminated candidiasis in leukemic patients [207].

Malassezia furfur, a lipophilic yeast, colonizes normal skin and is also the causative agent of tinea versicolor. In cancer patients, it has been associated with catheter-related sepsis in patients receiving parenteral lipids. In vitro, it is susceptible to amphotericin B and imidazoles. Therapy requires both catheter removal and discontinuation of parenteral lipids [208].

The dematiaceous soil fungi, Exophiala jeanselmei, E. pisciphila, E. spinifera, and Scedosporium inflatum, have caused infection in neutropenic patients [209]. In particular, S. inflatum has been associated with catheterrelated fungemia, retinal lesions, esophagitis, and hepatosplenic infections [210]. In vitro, these organisms are resistant to amphotericin B and fluconazole. In early stage disease, wide and deep surgical excision or cryosurgery are most effective. Medical therapy has been disappointing. In small series, long-term itraconazole therapy has shown some success; however, relapse after treatment has been reported [211].

Several other fungi have been associated with infections in immunocompromised patients. Some of these include Rhodotorula rubra, Hansenula anomala, Geotrichum candidum, Saccharomyces cereviseae, Drechslera spp., Phialophora parasiticia, Acremonium spp., and Pichia farinosa. Infections 
with these organisms are primarily associated with central venous catheters [212,213].

Recently, Pneumocystis carinii has been reclassified as a fungus based on DNA homology. This organism results in pneumonia and is the most common opportunistic infection in HIV-infected patients. Although infrequent, the incidence is increasing in patients with underlying malignancies. In the $1970 \mathrm{~s}$, most cancer patients who developed Pneumocystis carinii pneumonia (PCP) had hematologic malignancies. However, in the 1980s the incidence of PCP increased most among patients with solid organ tumors. Indeed, $31 \%$ of patients who developed PCP had primary or metastatic brain tumors. The increase in patients with brain tumors has been attributed to more intensive chemotherapeutic regimens and the use of higher doses of corticosteroids $[45,214]$. The concomitant decrease in patients with hematologic malignancies and those undergoing bone marrow transplantation reflects the use of PCP prophylaxis in this patient population.

\subsection{Protozoa and parasites}

Toxoplasma gondii is an intracellular protozoan parasite. Reactivation of $T$. gondii has been reported in cancer patients. In fact, more than one third of the cases of toxoplasmosis in non-HIV patients occurs in patients with Hodgkin's disease or leukemia. Toxoplasmosis is associated with corticosteroid use and can present with pneumonitis, uveitis, or central nervous system disease. The diagnosis of reactivation disease includes an assay for specific toxoplasma $\operatorname{IgG}$ antibodies. However, in an immunocompromised patient, the IgG titer is often low and IgM assays may be negative. In this situation, a definitive diagnosis of toxoplasmosis depends on the demonstration of the tachyzoites on tissue histology or on specific $T$. gondii DNA by the polymerase chain reaction (PCR). Chronic (latent) asymptomatic infection in immunodeficient patients is not treated; however, immunodeficient patients with acute infection should always be treated. The first-line therapy includes pyrimethamine and folinic acid plus either sulfadiazine or clindamycin for 4-6 weeks after resolution of all signs and symptoms of disease (often for 6 months or longer). For chronically immunosuppressed patients, particularly AIDS patients, acute treatment is followed by life-long maintenance therapy to prevent relapse of disease [215].

Cryptosporidium is an intracellular protozoan parasite first described in 1907 [216]. The first cases of human diarrhea were described in 1976, and today it is most commonly associated with diarrhea in patients with HIV [217]. It has also been detected with increasing frequency in patients with underlying hematologic malignancies, those who have undergone bone marrow transplantation, and those who are receiving corticosteroid therapy. In one review of 20 patients with hematologic malignancies and cryptosporidiosis, 5 patients had severe diarrhea, 10 had moderate diarrhea, and 5 were asymptomatic carriers. Extraintestinal cryptosporidiosis with pulmonary involvement was 
observed in one case. Resolution occurred spontaneously, although relapse was common, occurring in four patients [218]. Diagnosis is typically made by recognizing the characteristic oocysts in the material sampled, usually stool, duodenal aspirates, bile, or respiratory secretions. There is no reliable palliative or curative treatment for cryptosporidiosis. In immunocompetent or temporarily immunocompromised patients, the disease is self-limited. In patients who are irreversibly immunocompromised, therapy is symptomatic and supportive.

Strongyloides stercoralis is a nematode that can cause an overwhelming fatal infection in immunocompromised patients. S. stercoralis is increasingly recognized in patients with underlying hematologic malignancies, in patients treated with corticosteroids, and in patients with HIV. Humans are usually infected through skin contact with soil containing the infective filariform larvae or through autoinfection via the lower GI tract or perianal region by larvae that transform into infective organisms during their passage with feces. After infection and tissue invasion, the larvae enter the bloodstream and travel to the lungs. Here they break into the alveolar spaces and ascend to the glottis, where they are swallowed to reside in the small intestines. Contrary to most other worm infections, the patient's worm burden in strongyloidiasis is dependent not only on the size of the larval inoculum but also on the degree of autoinfection, which may be enhanced in immunocompromised hosts. This "autoinfection" cycle can result in an overwhelming larval invasion seen in strongylides hyperinfection syndrome, and these patients can develop massive larval invasion of the lungs and other tissues. This syndrome of hyperinfection strongyloidiasis is characterized by severe generalized abdominal pain, diffuse pulmonary infiltrates, ileus, shock, and meningitis or sepsis from gram-negative bacilli. Eosinophilia may be absent in the immunocompromised host. Definitive diagnosis is made by demonstrating the larvae in feces or in duodenal fluid. Thiabendazole is the only effective therapy; however, mortality remains very high in immunocompromised patients. Therefore, patients with a past history of exposure to $S$. stercoralis should be thoroughly examined and treated prior to receiving any immunosuppresive therapy [219-224].

\subsection{Other pathogens}

5.5.1 Bartonella spp. Bartonella (formerly Rickettsia) quintana and Bartonella (formerly Rochalimaea) henselae are slow-growing, motile, curved, gram-negative bacilli that have recently been recognized as human pathogens. Originally described in HIV patients, they have now been documented in cancer patients, including those with neutropenia. Both $B$. quintana and $B$. henselae can cause bacteremia or localized tissue infections, such as bacillary angiomatosis or bacillary peliosis. Bacillary angiomatosis was originally described in HIV patients as a neovascular proliferative disorder involving the 
skin and regional lymph nodes. Characteristically, the lesions are cutaneous, can number from few to hundreds, bleed copiously when incised, and may resemble Kaposi's sarcoma, from which they need to be differentiated. Bacillary angiomatosis involving the liver, spleen, bone, and brain has also been documented. Bacillary peliosis is a distinct clinical syndrome that is less dramatic than bacillary angiomatosis because its lesions are exclusively visceral and are only associated with nonspecific symptoms.

These organisms can be detected in blood cultures; however, they require prolonged periods of incubation. When they are suspected, the laboratory should be instructed to hold the blood cultures for up to 30 days. These organisms can also be detected in tissue biopsy specimens by Warthin-Starry staining or by electron microscopy. The initial treatment of choice is either oral doxycycline or oral erythromycin, often for prolonged periods of time. Tetracycline, minocycline, chloramphenicol, azithromycin, and clarithromycin have also been used successfully. Relapses can occur, and chronic suppressive therapy with doxycycline or erythromycin may need to be considered in these cases [225].

5.5.2 Prototheca wickerhamii. This unicellular, achloric algae is found in a wide range of environmental sites and has been isolated as the cause of infection in at least 61 cases. One was a child with Hodgkin's disease who had a central venous catheter in place and had $P$. wickerhamii isolated from the bloodstream [226]. The typical clinical presentation is a single lesion of the skin or subcutaneous tissue that gradually enlarges over weeks to months and may ulcerate. Characteristically, these lesions do not heal spontaneously. $P$. wickerhamii is resistant to fluconazole. Surgical debridement and amphotericin B have been used successfully [227-229].

\section{Summary}

Patients with underlying malignancies are at risk for a wide array of infectious diseases that cause significant morbidity and mortality. To develop a clear etiologic understanding of the infectious agents involved first requires a knowledge of the factors that predispose to infection. Neutropenia is clearly the single most important risk factor for infection in the cancer patient. However, a variety of both host and treatment-associated factors act together to predispose these patients to opportunistic infections. Approaching the individual malignancies with a knowledge of the underlying risk factors helps logically guide diagnosis and therapy. The astute clinician must also be aware of new and emerging infections in this patient population. As new pathogens are discovered and established pathogens become increasingly drug resistant, they will continue to present challenges for physicians caring for these patients in the years ahead. 


\section{References}

1. Chang H, Rodriguez V, Narboni G, et al. Causes of death in adults with acute leukemia. Medicine 1976;55:259-268.

2. Hughes WT. Fatal infections in childhood leukemia. Am J Dis Child 1971;122:283-287.

3. Hersh EM, Bodey GP, Nies BA, et al. Causes of death in acute leukemia. JAMA 1965;193:99-103.

4. Morrittu L, Earl HM, Souhami RL, et al. Patients at risk of chemotherapy-associated toxicity in small cell lung cancer. Br J Cancer 1989;59:801-804.

5. Viscoli C, Castagnola E. Factors predisposing cancer patients to infection. In: Klastersky J, ed. Infectious Complications of Cancer. Boston: Kluwer Academic, 1995, pp. 1-30.

6. Bodey GP, Buckley M, Sathe YS, et al. Quantitative relationships between circulating leukocytes and infection in patients with acute leukemia. Ann Intern Med 1966;64:328340.

7. Feld R, Bodey GP. Infections in patients with malignant lymphoma treated with combination chemotherapy. Cancer 1977;39:1018-1025.

8. Glauser MP, Zinner SH. Mechanisms of acquisition and development of bacterial infections in cancer patients. In: Klastersky J, ed. Infections in Cancer Patients. New York: Raven Press, 1982, pp. 13-30.

9. De Jongh CS, Joshi JH, Newman KA, et al. Antibiotic synergism and response in gramnegative bacteremia in granulocytopenic cancer patients. Am J Med 1986;80:96-100.

10. Wade JC, Schimpff SC. Epidemiology and prevention of infection in the compromised host. In: Rubin RH, Young LS, eds. Clinical Approach to Infection in the Compromised Host. New York: Plenum Medical, 1988, pp. 5-40.

11. Dale DC, Guerry DI, Wewerka JR, et al. Chronic neutropenia. Medicine 1979;58:128-144.

12. Viscoli C, Bruzzi P, Castagnola E, et al. Factors associated with bacteraemia in febrile, granulocytopenic cancer patients. Eur J Cancer 1994;30A:430-437.

13. The EORTC International Antimicrobial Therapy Project Group. Three antibiotic regimens in the treatment of infection in febrile granulocytopenic patients with cancer. J Infect Dis 1978;137:14-29.

14. Schimpff SC, Young VM, Greene WH, et al. Origin of infection in acute nonlymphocytic leukemia: Significance of hospital acquisition of potential pathogens. Ann Intern Med $1972 ; 77: 707-714$.

15. The EORTC International Antimicrobial Therapy Project Group. Ceftazidime combined with a short or long course of amikacin for empirical therapy of gram-negative bacteremia in cancer patients with granulocytopenia. N Engl J Med 1987:317:1692-1698.

16. Johanson WG, Pierce AK, Sanford JP. Changing pharyngeal bacterial flora of hospitalized patients. Emergence of gram-negative bacilli. N Engl J Med 1969;281:1137-1140.

17. Cometta A, Calandra T, Bille J, et al. Escherichia coli resistant to fluoroquinolones in patients with cancer and neutropenia. N Engl J Med 1994;330:1240-1241.

18. Levine SS, Schimpff SC, Graw RG Jr., et al. Hematologic malignancies and other marrow failure states: Progress in the management of complicating infections. Semin Hematol 1974;11:141-202.

19. Chanock S. Evolving risk factors for infectious complications of cancer therapy. Hematol Oncol Clin North Am 1993;7:771-793.

20. Koll BS, Brown AE. Changing patterns of infection in the immunocompromised patient with cancer. Hematol Oncol Clin North Am 1993;7:753-769.

21. Guiot HFL, Fibbe WE, van`t Wout JW. Risk factors for fungal infection in patients with malignant hematologic disorders: Implications for empirical therapy and prophylaxis. Clin Infect Dis 1993;18:525-532.

22. Warren JR, Scarpelli DG, Reddy JK, et al. Chronic inflammation and repair. In: Essentials of General Pathology. New York: Macmillan, 1987, pp. 27-46.

23. Johnston RB, Jr. Monocytes and macrophages. N Engl J Med 1988;318:747-752. 
24. Young RC, Corder MP, Haynes HA, et al. Delayed hypersensitivity in Hodgkin's disease. A study of 103 untreated patients. Am J Med 1972;52:63-72.

25. Seligmann M, Chess L, Fahey JL, et al. AIDS - An immunologic reevaluation. N Engl J Med 1984;311:1286-1292.

26. Aubertin J, Lacut JY, Hoerni B, et al. Factors favoring infections in cancer patients. In: Armstrong D, ed. Opportunistic Infections in Cancer Patients. New York: Masson, 1978, pp. $16-28$.

27. Krick $\mathbf{J}$, Remington $\mathbf{J}$. Opportunistic fungal infection in patients with leukemia and lymphoma. Clin Hematol 1976;5:249-310.

28. Lum LG. Immune recovery after bone marrow transplantation. Bone Marrow Transplant Hematol Oncol Clin North Am 1990;4:659-675.

29. Whittaker K, Rees K, Clark CG. Reduced lymphocyte transformation in breast cancer. Lancet 1971;1:892-893.

30. Han T, Takita H. Immunologic impairment in bronchogenic carcinoma: A study of lymphocyte response to phytohemagglutinin. Cancer 1972;30:616-620.

31. Brooks WH, Netsky MG, Normansell DE, et al. Depressed cell-mediated immunity in patients with primary intracranial tumors. J Exp Med 1972;136:1631-1647.

32. Orita $\mathrm{K}$, Miwa $\mathrm{H}$, Fukada $\mathrm{H}$, et al. Preoperative cell-mediated immune status of gastric cancer patients. Cancer 1976;38:2343-2348.

33. Schellhammer PF, Bracken RB, Bean MA, et al. Immune evaluation with skin testing. A study of testicular, prostate and bladder neoplasms. Cancer 1976;38:149-156.

34. Mackall CL, Fleisher TA, Brown MR, et al. Lymphocyte depletion during treatment with intensive chemotherapy for cancer. Blood 1994;84:2221-2228.

35. Mackall CL, Fleisher TA, Brown MR, et al. Age, thymopoiesis, and CD4 + T-lymphocyte regeneration after intensive chemotherapy. N Engl J Med 1995;332:143-149.

36. Kim JH, Perfect JR. Infection and cyclosporine. Rev Infect Dis 1989:11:677-690.

37. Bishop JF, Schimpff SC, Diggs CH, et al. Infections during intensive chemotherapy for nonHodgkin's lymphoma. Ann Intern Med 1981;95:549-555.

38. Bookman MA, Longo DL. Concomitant illness in patients treated for Hodgkin's disease. Cancer Treat Rev 1986;13:77-111.

39. Hardy I, Gershon AA, Steinberg SP, et al. The incidence of zoster after immunization with live attenuated varicella vaccine. N Engl J Med 1991;325:1545-1550.

40. Hughes WT, Townsend TR. Nosocomial infections in immunocompromised children. Am J Med 1981;70:412-416.

41. Ampel NM, Wing EJ. Legionellosis in the compromised host. In: Rubin RH, Young LL, eds. Clinical Approach to Infection in the Compromised Host. New York: Plenum Medical, 1988, pp. 305-319.

42. Luft BJ, Remington JS. Toxoplasmosis of the central nervous system. Curr Clin Top Infect Dis 1985;6:315-358.

43. Longworth DL, Weller PF. Hyperinfection syndrome with strongyloidiasis. Curr Clin Top Infect Dis 1986;7:1-26.

44. Varthalitis I, Meunier F. Pneumocystis carinii pneumonia in cancer patients. Cancer Treat Rev 1993;19:387-413.

45. Sepkowitz KA, Brown AE, Telzak EE, et al. Pneumocystis carinii pneumonia among patients without AIDS at a cancer hospital. JAMA 1992;267:832-837.

46. Sepkowitz KA. Pneumocystis carinii pneumonia in patients without AIDS. Clin Infect Dis 1993;17(Suppl. 2):S416-S422.

47. Hughes WT, Feldman S, Aur RJA, et al. Intensity of immunosuppressive therapy and the incidence of Pneumocystis carinii pneumonitis. Cancer 1975;36:2004-2009.

48. Salmon SE. Immunoglobulin synthesis and tumor kinetics of multiple myeloma. Semin Hematol 1973;10:135-147.

49. Fahey JL, Scoggins R, Utz JP, et al. Infection, antibody response and gamma globulin components in multiple myeloma and macroglobulinemia. Am J Med 1963;35: 698-707. 
50. Jacobson DR, Zolla-Pazner S. Immunosuppression and infection in multiple myeloma. Semin Oncol 1986;13:282-290.

51. Mordasini RC, Keller H, Schlumpf E, et al. Humorale Infektabwherschwache bei paraproteinamischen Erkrankungen. Schewiz Med Wschr 1972;102:625-635.

52. Homberg JC, Cartron J, Ropars C, et al. Anomalies immunologiques observees au cours des leucemies lymphoides chroniques hyperlymphocytaires. Nouv Rev Fr Hematol 1971;11:476483.

53. Sheridan JF, Tutschka PJ, Sedmak DD, et al. Immunoglobulin G subclass deficiency and pneumococcal infection after allogeneic bone marrow transplantation. Blood 1990;75:15831586.

54. Atkinson K. Reconstruction of the haemopoietic and immune systems after bone marrow transplantation. Bone Marrow Transpl 1990;5:209-226.

55. Axelrod PI, Lorber B, Vonderheid EC. Infections complicating mycosis fungoides and Sezary syndrome. JAMA 1992;267:1354-1358.

56. Awada A, van der Auwera P, Meunier F, et al. Streptococcal and enterococcal bacteremia in patients with cancer. Clin Infect Dis 1992;15:33-48.

57. Hosea SW, Brown EJ, Hamburger MI, et al. Opsonic requirements for intravascular clearance after splenectomy. N Engl J Med 1981;304:245-250.

58. Van Der Meer JWM. Defects in host-defense mechanisms. In: Rubin RH, Young LS, eds. Clinical Approach to Infection in the Compromised Host. New York: Plenum Medical, 1988, pp. 41-63.

59. Gopal V, Bison AL. Fulminant pneumococcal infections in "normal" asplenic hosts. Arch Intern Med 1977;137:1526-1530.

60. Advisory Committee on Immunization Practices. Pneumococcal polysaccharide vaccine. MMWR 1989;38:64-68, 73-76.

61. Kahls P, Kier P, Lechner K. Functional asplenia after bone marrow transplantation. Ann Intern Med 1990;114:805-806.

62. Schimpff SC. Infections in the cancer patient - Diagnosis, prevention, and treatment. In: Mandell GL, Bennett JE, Dolin R, eds. Principles and Practices of Infectious Diseases. New York: Churchill Livingstone, 1995, pp. 2666-2675.

63. Schwartz SN, Dowling JN, Benkovic C, et al. Sources of gram-negative bacilli colonizing the trachea of intubated patients. J Infect Dis 1978;138:227-231.

64. Kelly CP, Pothoulakis C, Lamont JT. Clostridium difficle colitis. N Engl J Med 1994;330:257262.

65. Anand A, Glatt A. Clostridium difficle infection associated with antineoplastic chemotherapy: A review. Clin Infect Dis 1993;17:109-113.

66. Fan-Havard P, Capano D, Smith SM, et al. Development of resistence in Candida isolates from patients receiving prolonged antifungal therapy. Antimicrob Agents Chemother 1978;35:2302-2305.

67. Meunier F, Aoun M, Bitar N. Candidemia in immunocompromised patients. Clin Infect Dis 1992;14(Suppl. 1):S120-S125.

68. Boken DJ, Swindells S, Rinaldi MG. Fluconazole-resistant Candida albicans. Clin Infect Dis 1993;17:1018-1021.

69. Aisner J, Schmipff SC, Sutherland JC, et al. Torulopsis glabrata infections in patients with cancer. Am J Med 1976;61:23-28.

70. Merz WG, Karp JE, Schron D, et al. Increased incidence of fungemia caused by Candida krusei. J Clin Microbiol 1986;24:581-584.

71. Wingard JR, Merz WG, Rinaldi MG, et al. Increase in Candida krusei infection among patients with bone marrow transplantation and neutropenia treated prophylactically with fluconazole. N Engl J Med 1991;325:1274-1277.

72. van der Waaij DD, Berghuis J, Lekkerkerk JEC. Colonization resistance of the digestive tract of mice during systemic antibiotic treatment. J Hyg (Camb) 1972;70:605-610.

73. Wilson BD, Surgalla MJ, Yates JW. Aerobic and anaerobic surgical wound contamination in patients with cancer. Surg Gynecol Obstet 1974;139:329-332. 
74. Rolandelli R, Roslyn JJ. The colon and rectum. Surgical anatomy and operative procedures. In: Sabiston DCJ, Lyerly HK, eds. Textbook of Surgery. The Biological Basis of Modern Surgical Practice. Philadelphia: W.B. Saunders, 1997, pp. 971-975.

75. Gongaware RD, Slanetz CAJ. Hartmann procedure for carcinoma of the sigmoid and rectum. Ann Surg 1973;178:28-30.

76. Naito H, Toya S, Shizawa $\mathrm{H}$, et al. High incidence of acute post operative meningitis and septicemia in patients undergoing craniotomy with vertriculoatrial shunt. Surg Gynecol Obstet 1973;137:810-812.

77. Geelhoed GW, Ketcham AS. Pseudomonas meningitis complicating radical resection for radiorecurrent cancer of paranasal sinuses: Report of two patients successfully treated with intrathecal polymyxin. J Surg Oncol 1973;5:365-374.

78. Harris M, Gumport S, Berman I, et al. Ilioinguinal lymph node dissecton for melanoma. Surg Gynecol Obstet 1973;136:33-39.

79. Villar HV, Warneke JA, Peck MD, et al. Role of surgical treatment in the management of complications of the gastrointestinal tract in patients with leukemia. Surg Gynecol Obstet 1987;165:217-222.

80. Wade DS, Nava HR, Douglass HOJ. Neutropenic enterocolitis. Clinical diagnosis and treatment. Cancer 1992;69:17-23.

81. Schimpff SC, O'Connel MJ, Greene WH, et al. Infections in 92 splenectomized patients with Hodgkin's disease. Am J Med 1975;59:695-701.

82. Say CC, Donegan W. A biostatistical evaluation of complications from mastectomy. Surg Gynecol Obstet 1974;138:370-376.

83. Smith MGM, Golding PL, Eddleston ALWF, et al. Cell-mediated immune responses in chronic liver diseases. Br Med J 1972;1:527-530.

84. Castagnola E, Garaventa A, Conte M, et al. Survival after fungemia due to Fusarium moniliforme in a child with neuroblastoma [letter]. Eur J Clin Microbiol Infect Dis 1993;12:308-309.

85. Wade JC, Schimpff SC, Hargadon MT, et al. A comparison of trimethoprimsulfamethoxazole plus nystatin with gentamicin plus nystatin in the prevention of infections in acute leukemia. N Engl J Med 1981;304:1057-1062.

86. Schimpff SC, Greene WH, Young WM, et al. Infection prevention in acute nonlymphocytic leukemia. Ann Intern Med 1975;82:351-358.

87. Hathorn JW. Critical appraisal of antimicrobials for prevention of infections in immunocompromised hosts. Hematol Oncol Clin North Am 1993;7:1051-1099.

88. McQuillen DP, Zingman BS, Meunier F, et al. Invasive infections due to Candida krusei: Report of ten cases of fungemia that include three cases of endophthalmitis. Clin Infect Dis 1992;14:472-478.

89. Shlaes DM, Binezewski B, Rice BL. Emerging antimicrobial resistance and the immunocompromised host. Clin Infect Dis 1993;17(Suppl. 2):S527-536.

90. Stosor V, Noskin GA, Peterson LR. The management and prevention of vancomycinresistant enterococci. Infect Med 1996;13:488, 493-498.

91. Livornese LL, Dias S, Samel C, et al. Hospital-acquired infection with vancomycin-resistant Enterococcus faecium transmitted by electronic thermometers. Ann Intern Med 1992;117:112-116.

92. Groeger JS, Lucas AB, Thaler HT, et al. Venous access devices in patients with cancer. Ann Intern Med 1993;119:1168-1174.

93. Tenney JH, Moody MR, Newman KA, et al. Adherent microorganisms on lumenal surfaces of long-term intravenous catheters. Arch Intern Med 1986;146:1949-1954.

94. Pizzo PA. Management of fever in patients with cancer and treatment-induced neutropenia. N Engl J Med 1993;328:1323-1332.

95. Clarke DE, Raffin TA. Infectious complications of indwelling long-term central venous catheters. Chest 1990;97:966-972.

96. Abi-Nader JA. Peripherally inserted central venous catheters in critical care patients. Heart Lung 1993;22:428-434. 
97. Lam S, Scannell R, Roessler D, et al. Peripherally inserted central catheters in an acute-care hospital. Arch Intern Med 1994;154:1833-1837.

98. Loughran SC, Borzatta M. Peripherally inserted central catheters: A report of 2506 catheter days. J Parent Ent Nut 1995;19:133-136.

99. Gottesdiener KM. Transplanted infections: Donor-to-host transmission with the allograft. Ann Intern Med 1989;110:1001-1016.

100. Barbara JAJ, Contreras M. Infectious complications of blood transfusion: Bacteria and parasites. Br Med J 1990;300:386-389.

101. Soulier JP. Diseases tramsmissible by blood transfusion. Vox Sang 1984;47:1-6.

102. Alter HJ, Purcell RH, Shih JW, et al. Detection of antibody to hepatitis C virus in prospectively followed transfusion recipients with acute and chronic non-A, non-B hepatitis. $\mathrm{N}$ Engl J Med 1989;321:1494-1500.

103. Sayers MH, Anderson KC, Goodnough LT, et al. Reducing the risk for transfusiontransmitted cytomegalovirus infection. Ann Intern Med 1992;116:55-62.

104. Mayer KH, Opal SM. Unusual nosocomial pathogens. Infect Dis Clin North Am 1989;3:883 899.

105. Wittner M, Rowin KS, Tanowitz HB, et al. Successful chemotherapy for transfusion babesiosis. Ann Intern Med 1982;96:601-604.

106. Tabor E, Garety RJ. Five cases of Pseudomonas sepsis transmitted by blood transfusions. Lancet $1984 ; 1: 1403$.

107. Wright DC, Selss IF, Vinton KJ, et al. Fatal Yersinia enterocolitica sepsis after blood transfusion. Arch Pathol Lab Med 1985;109:1040-1042.

108. Yomtovian R, Lazarus LT, Goodnough NV, et al. A prospective microbiologic surveillance program to detect and prevent the transfusion of bacterially contaminated platelets. Transfusion 1993:33:902-909.

109. Schimpff SC. Therapy of infection in patients with granulocytopenia. Med Clin North Am 1977;61:1101-1118.

110. Bodey GP, Rodriguez V, Chang $\mathrm{H}$, et al. Fever and infection in leukemic patients. A study of 494 consecutive patients. Cancer 1978;41:1610-1622.

111. Sanders JW, Powe NR, Moore RD. Ceftazidime monotherapy for empiric treatment of febrile neutroenic patients: A metaanalysis. J Infect Dis 1991;164:907-916.

112. Sanders CC. New B-lactams: New problems for the internist. Ann Intern Med 1991;115:650 651 .

113. Whimbey E, Kiehn TE, Brannon P, et al. Bacteremia and fungemia in patients with neoplastic disease. Am J Med 1987;82:723-730.

114. Singer C, Kaplan MH, Armstrong D. Bacteremia and fungemia complicating neoplastic disease. Am J Med 1977;62:731-742.

115. The EORTC International Antimicrobial Therapy Cooperative Group. Gram-positive bacteremia in granulocytopenic cancer patients. Eur J Cancer 1990;26:569-574.

116. Viscoli C, Van der Auwera P, Meunier F. Gram-positive infections in granulocytopenic patients: An important issue? J Antimicrob Chemother 1988;21(Suppl. C):149-156.

117. Winston DJ, Dudnick DV, Chapin M, et al. Coagulase-negative staphylococcal bacteremia in patients receiving immunosuppressive therapy. Arch Intern Med 1983;143: 32-36.

118. Karp JE, Dick J, Angelopulos C, et al. Empiric use of vancomycin during prolonged treatment-induced granulocytopenia: Randomized, double-blind, placebo-controlled clinical trial in patients with acute leukemia. Am J Med 1986;81:237-242.

119. Arning M, Gehrt A, Aul C, et al. Septicemia due to Streptococcus mitis in neutropenic patients with acute leukemia. Blut 1990;61:364-368.

120. Neu HC. The crisis in antibiotic resistance. Science 1992;257:1064-1073.

121. Anaissie E. Opportunistic mycoses in the immunocompromised host: Experience at a cancer center and review. Clin Infect Dis 1992;14(Suppl. 1):S43-53.

122. Meunier-Carpentier F, Kiehn TE, Armstrong D. Fungemia in the immunocompromised host: Changing patterns, antigenemia, high mortality. Am J Med 1981;71:363-370. 
123. Lecciones JA, Lee JW, Navarro EE, et al. Vascular catheter-associated fungemia in patients with cancer: Analysis of 155 episodes. Clin Infect Dis 1992;14:875-883.

124. Wey SB, Mori M, Pfaller MA, et al. Hospital-acquired candidemia: The attributable mortality and excess length of stay. Arch Intern Med 1988;148:2642-2645.

125. Gerson SL, Talbot GH, Hurwitz S, et al. Prolonged granulocytopenia: The major risk factor for invasive pulmonary aspergillosis in patients with acute leukemia. Ann Intern Med 1984;100:345-351.

126. Fischer BD, Armstrong D, Yu B, et al. Invasive aspergillosis: Progress in early diagnosis and treatment. Am J Med 1981;71:571-577.

127. De Gregorio M, Lee W, Linker C, et al. Fungal infections in patients with acute leukemia. Am J Med 1982;73:543-548.

128. Hawkins C, Armstrong D. Fungal infections in the immunocompromised host. Clin Haematol 1984;3:599-630.

129. Bodey G, Bueltmann B, Duguid W, et al. Fungal infections in cancer patients: An international autopsy survey. Eur J Microbiol Infect Dis 1992;11:99-109.

130. Corey L, Spear PG. Infections with Herpes simplex virus. N Engl J Med 1986;314:686-691, 749-757.

131. Rand KH, Kramer B, Johnson AC. Cancer chemotherapy associated symptomatic stomatitis: Role of Herpes simplex virus (HSV). Cancer 1982;50:1262-1265.

132. Buss DH, Scharyj M. Herpesvirus infection of the esophagus and other visceral organs in adults: Incidence and clinical significance. Am J Med 1979;66:457-462.

133. Ramsey PG, Fife KH, Hackman RC, et al. Herpes simplex virus pneumonia: Clinical, virologic, and pathologic features in 20 patients. Ann Intern Med 1982:97:813-820.

134. Straus SE, Ostrove JM, Inchauspe G, et al. Varicella-zoster virus infections: Biology, natural history, treatment, and prevention. Ann Intern Med 1988;108:221-237.

135. Meyers JD, Flournoy N, Thomas ED. Risk factors for cytomegalovirus infection after human marrow transplantation. J Infect Dis 1986;153:478-488.

136. Kaplan LJ, Daum RS, Smaron M, et al. Severe measles in immunocompromised patients. JAMA 1992;267:1237-1241.

137. Zahradnik JM, Spencer MJ, Porter DD. Adenovirus infection in the immunocompromised patient. Am J Med 1980;68:725-732.

138. Meunier F. Infections in patients with acute leukemia and lymphoma. In: Mandell GL, Bennett JE, Dolin R, eds. Principles and Practices of Infectious Diseases. New York: Churchill Livingstone, 1995, pp. 2675-2686.

139. Cotran RS, Kumar V, Robbins SL. Diseases of white cells, lymph nodes, and spleen. In: Robbins Pathologic Basis of Disease. Philadelphia: W.B. Saunders, 1989, pp. 703-754.

140. Goyal R, Bajpai S, Chopra HK, et al. Hairy cell leukemia - an unusual presentation. Leuk Res 1995;19:485-487.

141. Mackowiak PA, Demian SE, Sutker WL, et al. Infections in hairy cell leukemia: Clinical evidence of a pronounced defect in cell-mediated immunity. Am J Med 1980;68:718-723.

142. Bennett C, Vardiman J, Golomb H. Disseminated atypical mycobacterial infection in patients with hairy cell leukemia. Am J Med 1966;80:891-896.

143. Attal M, Schlaifer D, Rubie H, et al. Prevention of gram-positive infections after bone marrow transplantation by systemic vancomycin: A prospective, randomized trial. $\mathrm{J}$ Clin Oncol 1991;9:865-870.

144. Goodman JL, Winston DJ, Greenfield RA, et al. A controlled trial of fluconazole to prevent fungal infections in patients undergoing bone marrow transplantation. $\mathrm{N}$ Engl $\mathrm{J}$ Med 1992;326:845-851.

145. Goodrich JM, Reed EC, Mori M, et al. Clinical features and analysis of risk factors for invasive candidal infection after marrow transplantation. J Infect Dis 1991;164:731-740.

146. Derouin F, Devergie A, Auber P, et al. Toxoplasmosis in bone marrow-transplant recipients: Report of seven cases and review. Clin Infect Dis 1992;15:267-270.

147. Miller W, Flynn P, McCulough J, et al. Cytomegalovirus infection after bone marrow transplantation: An association with acute graft-v-host disease. Blood 1986;67:1162-1167. 
148. Wingard JR, Mellits D, Sostrin MB, et al. Interstitial penumonitis after allogeneic bone marrow transplantation: Nine year experience at a single institution. Medicine 1988;67:175-186.

149. Pannuti CS, Gingrich RD, Pfaller MA, et al. Nosocomial pneumonia in adult patients undergoing bone marrow transplantation: A 9 year study. J Clin Oncol 1991;9:77-84.

150. Meyers JD, Thomas ED. Infection complicating bone marrow transplantation. In: Rubin RH, Young LS, eds. Clinical Approach to Infection in the Compromised Host. New York: Plenum Medical, 1988, pp. 525-556.

151. Hiemenz JW, Greene JN. Special considerations for the patient undergoing allogeneic or autologous bone marrow transplantation. Hematol Oncol Clin North Am 1993;7:961-1002.

152. Rubin RH, Ferraro MJ. Understanding and diagnosing infectious complications in the immunocompromised host. Hematol Oncol Clin North Am 1993;7:795-812.

153. Cohen ML. Epidemiology of drug resistance: Implications for a post-antimicrobial era. Science 1992;257:1050-1055.

154. Kunin CM. Resistance to antimicrobial drugs - A worldwide calamity. Ann Intern Med 1993;118:557-561.

155. Leclercq R, Derlot E, Duval J, et al. Plasmid-mediated resistance to vancomycin and teicoplanin in Enterococcus faecium. N Engl J Med 1988;319:157-161.

156. Montecalvo MA, Horowitz H, Gedris C, et al. Outbreak of vancomycin-, ampicillin-, and aminoglycoside-resistant Enterococcus faecium bacteremia in an adult oncology unit. Antimicrob Agents Chemother 1994;38:1363-1367.

157. Noskin GA, Cooper I, Peterson L. Vancomycin-resistant Enterococcus faecium sepsis following persistent colonization. Arch Intern Med 1995;155:1445-1447.

158. Infectious Diseases Society of America. IDSA disseminates the latest on infectious diseases. Infect Dis Alert 1996;16:38-39.

159. Bouchud PY, Calandra T, Francioli P. Bacteremia due to viridans streptococci in neutropenic patients: A review. Am J Med 1994;97:256-264.

160. Kern W, Kurrle E, Schmeiser T. Streptococcal bacteremia in adult patients with leukemia undergoing aggressive chemotherapy. A review of 55 cases. Infection 1990;18:138-145.

161. Elting LS, Bodey GP, Keefe BH. Septicimia and shock syndrome due to viridans streptococci: A case-control study of predispoisng factors. Cin Infect Dis 1992;14:1201-1207.

162. Borek AP, Dressel DC, Hussong J, et al. Changing susceptibility of Streptococcus pneumoniae to antimicrobial agents in Chicago, Illinois between 1993 and 1996: The need for accurate laboratory identification and susceptibility testing. Diagn Microbiol Infect Dis 1997:29:209-214.

163. Handwerger S, Horowitz H, Coburn K, et al. Infection due to Leluconostoc species: Six cases and review. Rev Infect Dis 1990;12:602-610.

164. Ascher DP, Zbick C, White C, et al. Infections due to Stomatococcus mucilaginosus: 10 cases and review. Rev Infect Dis 1991;13:1048-1052.

165. McWhinney PH, Kibbler CC, Gillespie SH, et al. Stomatococcus mucilaginosus: An emerging pathogen in neutropenic patients. Clin Infect Dis 1992;14:641-646.

166. Young VM, Meyers WF, Moody MR, et al. The emergence of coryneform bacteria as a cause of nosocomial infections in compromised hosts. Am J Med 1981;70:646-650.

167. Riebel W, Frantz N, Adelstein D, et al. Corynebacterium JK: A cause of nosocomial devicerelated infection. Rev Infect Dis 1986;8:42-49.

168. Johnson A, Hulse P, Oppenheim BA. Corynebacterium jeikeium meningitis and transverse meylitis in a neutropenic patient. Eur J Clin Microbiol Infect Dis 1992;11:473-474.

169. Henrickson K, Shenep J, Flynn P, et al. Primary cutaneous Bacillus cereus infection in neutropenic children. Lancet 1989;1:601-603.

170. Tuazon CU. Other Bacillus species. In: Mandell GL, Bennett JE, Dolin R, eds. Principles and Practice of Infectious Diseases. New York: Churchill Livingstone, 1995, pp. 1890-1894.

171. Harvey RL, Sunstrum JC. Rhodococcus equi infection in patients with and without human immunodeficiency virus infection. Rev Infect Dis 1991;13:139-145.

172. Khardori N, Elting L, Wong E, et al, Nosocomial infections due to Xanthomonas maltophilia (Pseudomonas maltophilia) in patients with cancer. Rev Infect Dis 1990;12:997-1003. 
173. Garau J. Beta-lactamases: Current situation and clinical importance. Intensive Care Med 1994;20:S5-S9.

174. Sirot D. Extended-spectrum plasmid-mediated B-lactamases. J Antimicrob Chemother 1995;36(Suppl. A):19-34.

175. Meyer KS, Urban C, Eagan JA, et al. Nosocomial outbreak of Klebsiella infection resistant to late-genertation cephalosporins. Ann Intern Med 1993:119:353-358.

176. Pegues DA, Carson LA, Anderson RL, et al. Outbreak of Pseudomonas cepacia bacteremia in oncology patients. Clin Infect Dis 1993;16:407-411.

177. Kaye KM, Macone A, Kazanjian PH. Catheter infection caused by Methylobacterium in immunocompromised hosts: Report of three cases and review of the literature. Clin Infect Dis 1992;14:1010-1014.

178. Edmond MB, Riddler SA, Baxter CM, et al. Agrobacterium radiobacter: A recently recognized opportunistic pathogen. Clin Infect Dis 1993;16:388-391.

179. Cieslak TJ, Robb ML, Drabick CJ, et al. Catheter-associated sepsis caused by Ochrobactrum anthropi: Report of a case and review of related nonfermentative bacteria. Clin Infect Dis 1992;14:902-907.

180. Legrand C, Anaissie E. Bacteremia due to Achromobacter xylosoxidans in patients with cancer. Clin Infect Dis 1992;14:479-484.

181. Kim JH, Cooper RA, Welty-Wolf KE, et al. Pseudomonas putrefaciens bacteremia. Rev Infect Dis 1989;11:97-104.

182. Bilgrami S, Bergstrom SK, Peterson DE, et al. Capnocytophaga bacteremia in a patient with Hodgkin's disease following bone marrow transplantation: Case report and review. Clin Infect Dis 1992;14:1045-1049.

183. Lorber B. Gas gangrene and other Clostridium-associated diseases. In: Mandell GL, Bennett JE, Dolin R, eds. Principles and Practice of Infectious Diseases. New York: Churchill Livingstone, 1995, pp. 2182-2195.

184. Valtonen M, Sivonen A, Elonen E. A cluster of seven cases of Clostridium tertium septicemia in neutropenic patients. Eur J Clin Microbiol Infect Dis 1990;9:40-42.

185. Zinner SH. New and unusual infections in neutropenic patients. In: Klastersky J, ed. Infectious Complications of Cancer. Boston: Kluwer Academic, 1995, pp. 173-184.

186. Huyghebaert MF, Dreyfus F, Paul G, et al. Septicemie a Fusobacterium nucleatum, producteur de beta-lactamase chez un sujet neutropenique. Ann Med Interne (Paris) 1989:140:225-226.

187. Weinberger $\mathrm{M}, \mathrm{Wu} \mathrm{T}$, Rubin $\mathrm{M}$, et al. Leptotricha buccalis bacteremia in patients with cancer: Report of four cases and review. Rev Infect Dis 1991;13:201-206.

188. Simon HB. Mycobacterial and nocardial infections in the compromised host. In: Rubin RH, Young LS, eds. Clinical Approach to Infection in the Compromised Host. New York: Plenum, 1988, pp. 221-251.

189. McWhinney PH, Yates M, Prentice HG, et al. Infection caused by Mycobacterium chelonae: A diagnostic and therapeutic problem in the neutropenic patient. Clin Infect Dis 1992:14:1208-1212.

190. Raad I.I., Vartivarian S, Khan A, et al. Catheter-related infections caused by the Mycobacterium fortuitum complex: 15 cases and review. Rev Infect Dis 1991;13:1120-1125.

191. Kristjansson M, Bieluch VM, Byeff PD. Mycobacterium haemophilum infection in immunocompromised patients: Case report and review of the literature. Rev Infect Dis 1991;13:906-910.

192. Chatis PA, Crumpacker CS. Resistance of Herpesviruses to antiviral drugs. Antimicrob Agents Chemother 1992;36:1589-1595.

193. Lalezari J, Stagg R, Kupperman B, et al. Intravenous cidofovir for peripheral Cytomegalovirus retinitis in patients with AIDS. Ann Intern Med 1997;126:257-263.

194. Studies of ocular complications of AIDS Research Group and the AIDS Clinical Trials Group. Parenteral cidofovir for Cytomegalovirus retinitis in patients with AIDS: The HPMPC peripheral Cytomegalovirus retinitis trial. Ann Intern Med 1997;126:264274. 
195. Foreman KE, Friborg J, Kong W, et al. Propatation of a human Herpesvirus from AIDSassociated Kaposi's sarcoma. N Engl J Med 1997;336:163-171.

196. Strauchen JA, Hauser D, Burstein D, et al. Body cavity-based malignant lymphoma containing Kaposi sarcoma-associated Herpesvirus in an HIV-negative man with previous Kaposi sarcoma. Ann Intern Med 1996;125:822-825.

197. Pfaller M, Wenzel R. Impact of the changing epidemiology of fungal infections in the 1990's. Eur J Clin Microbiol Infect Dis 1992;11:287-291.

198. Walsh TJ, Lee J, Lecciones J, et al. Empiric therapy with amphotericin B in febrile granulocytopenic patients. Rev Infect Dis 1991;13:496-503.

199. Wingard J, Merz W, Saral R. Candida tropicalis: A major pathogen in immunocompromised patients. Ann Intern Med 1979;91:539-543.

200. Anaissie E, Bodey G. Nosocomial fungal infections: Old problems and new challenges. Infect Dis Clin North Am 1989;3:867-882.

201. Gamis AS, Gudnason T, Giebink GS, et al. Disseminated infection with Fusarium in recipients of bone marow transplants. Rev Infect Dis 1991;13:1077-1088.

202. Nucci M, Spector N, Lucena S, et al. Three cases of infection with Fusaritum species on neutropenic patients. Eur J Clin Microbiol Infect Dis 1992;11:1160-1162.

203. Bennett J. Miscellaneous fungi, and prototheca. In: Mandell G, Bennett J, Dolin R, eds. Principles and Practices of Infectious Diseases. New York: Churchill Livingstone, 1995, pp. 2389-2393.

204. Nahass GT, Rosenberg SP, Leonardi CL, et al. Disseminated infection with Trichosporon beigelii. Arch Dermatol 1993;129:1020-1023.

205. Walsh TJ, Newman KR, Moody M, et al. Trichosporonosis in patients with neoplastic disease. Medicine 1986;65:268-279.

206. Kalter DCA, Tschen JA, Cernoch PL, et al. Genital white piedra: Epidemiology, microbiology and therapy. J Am Acad Dermatol 1986;14:982-993.

207. Martino P, Venditti M, Micozzi A, et al. Blastoschizomyces capitatus: An emerging cause of invasive fungal disease in leukemia patients. Rev Infect Dis 1990;12:570-582.

208. Danker W, Spector S, Fierer J. Malassezia fungemia in neonates and adults: Complication of hyperalimentation. Rev Infect Dis 1987;9:743-837.

209. Sudduth E, AJ CI, WE F. Phaeohyphomycosis due to Exophiala species: Clinical spectrum of disease in humans. Clin Infect Dis 1992;15:639-644.

210. Wood GM, McCormack JG, Muir DB, et al. Clinical features of human infection with Scedosporium inflatum. Clin Infect Dis 1992;14:1027-1033.

211. Wagner KF. Agents of chromomycosis. In: Mandell GL, Bennett JE, Dolin R, eds. Principles and Practice of Infectious Diseases. New York: Churchill Livingstone, 1995, pp. 2324-2327.

212. Anaissie E, Bodey GP, Kantarjian H, et al. New spectrum of fungal infections in patients with cancer. Rev Infect Dis 1989;11:369-378.

213. Kiehn TE, Gorey E, Brown AE, et al. Sepsis due to Rhodotorula related to use of indwelling central venous catheters. Clin Infect Dis 1992;14:841-846.

214. Henson JW, Jalaj JK, Walker RW, et al. Pnetumocystis carinii pneumonia in patients with primary brain tumors. Arch Neurol 1991;48:406-409.

215. Beaman MH, McCabe RE, Wong S, et al. Toxoplasma gondii. In: Mandell GL, Bennett JE, Dolin R, eds. Principles and Practice of Infectious Diseases. New York: Churchill Livingstone, 1995, pp. 2455-2475.

216. Ledingham JCG, Penfold WJ, Woodcock HM. Recent bacteriological experiences with typhoidal disease and dysentery: With notes on the protozoan parasites in the excreta. $\mathrm{Br}$ Med J 1915;2:704-711.

217. Faust EC, Giraldo LE, Caicedo G. Human isosporosis in the western hemisphere. Am J Trop Med Hyg 1961;10:343-349.

218. Gentile G, Venditti M, Micozzi A, et al. Cryptosporidiosis in patients with hematologic malignancies. Rev Infect Dis 1991;13:842-846.

219. Plumelle Y, Edouard A. Strongyloides stercoralis in T-cell leukemia/lymphoma in adults and acquired immunodeficiency syndrome. Rev Med Interne 1996;17:125-129. 
220. Nucci M, Portugal R, Pulcheri W, et al. Strongyloidiasis in patients with hematologic malignancies. Clin Infect Dis 1995;21:675-677.

221. Savage D, Foadi M, Haworth C, et al. Marked eosinophilia in an immunosuppressed patient with strongyloidiasis. J Intern Med 1994;236:473-475.

222. Aydin H, Doppl W, Battmann A, et al. Opportunistic Strongyloides stercoralis hyperinfection in lymphoma patients undergoing chemotherapy and/or radiotherapy - report of a case and review of the literature. Acta Oncol 1994;33:78-80.

223. Simpson WG, Gerhardstein DC, Thompson JR. Disseminated Strongyloides stercoralis infection. South Med J 1993;86:821-825.

224. Wilkinson R, Leen CL. Chronic lymphocytic leukaemia and overt presentation of underlying Stronglyloides stercoralis infection. J Infection 1993;27:99-100.

225. Slater LN, Welch DF. Rochalimaea species (recently renamed Bartonella). In: Mandell GL, Bennett JE, Dolin R, eds. Principles and Practice of Infectious Diseases. New York: Churchill Livingstone, 1995, pp. 1741-1747.

226. Heney C, Greeff M, Davis V. Hickman catheter-related Protothecal algaemia in an immunocompromised child. J Infect Dis 1991;163:930-931.

227. Kwon-Chung KJ, Bennett JE. Medical Mycology. Philadelphia: Lea \& Febiger, 1992.

228. Kaminski ZC, Kapila R, Sharer LR, et al. Meningitis due to Prototheca wickerhamii in a patient with AIDS. Clin Infect Dis 1992;15:704-706.

229. Iacoviello VR, DeGirolami PC, Lucarini J, et al. Protothecosis complicating prolonged endotracheal intubation: Case report and literature review. Clin Infect Dis 1992;15:959-967. 